\title{
MAKING AN INTEGRATED DECISION IN A THREE-STAGE SUPPLY CHAIN ALONG WITH CELLULAR MANUFACTURING UNDER UNCERTAIN ENVIRONMENTS: A QUEUEING-BASED ANALYSIS*
}

\author{
Bahman Esmailnezhad ${ }^{1}$ And Mohammad SAidi-MehrabaD ${ }^{2,3, *}$
}

\begin{abstract}
Today's complicated business environment has underscored the importance of integrated decision-making in supply chains. In this paper, a novel mixed-integer nonlinear mathematical model is proposed to integrate cellular manufacturing systems into a three-stage supply chain to deal with customers' changing demands, which has been little explored in the literature. This model determines the types of vehicles to transport raw materials and final parts, the suppliers to procure, the priorities of parts to be processed, and the cell formation to configure work centers. In addition, queueing theory is used to formulate the uncertainties in demands, processing times, and transportation times in the model more realistically. A linearization method is employed to facilitate the tractability of the model. A genetic algorithm is also developed to deal with the NP-hardness of the problem. Numerous instances are used to validate the effectiveness of the modeling and the efficiency of solution procedures. Finally, a sensitivity analysis and a real case study are discussed to provide important management insights and evaluate the applicability of the proposed model.
\end{abstract}

Received April 27, 2021. Accepted September 8, 2021.

\section{INTRODUCTION}

Today, the intensifying competitive pressures in the marketplace mean that companies must meticulously consider all stages of the production process, from the procurement of raw materials to the delivery of finished products, in order to survive. Managing the material flow from suppliers to customers as a unified system rather than a sequence of independent actions is the fundamental philosophy of supply chain management [11]. The goal is to link procurement activities, manufacturing processes, distribution networks, and the marketplace. As a result, customers are served at a higher level and a lower cost, and manufacturers gain a competitive advantage through cost reduction and product augmentation [12,48]. In practical terms, integrated decision-making is significant in industries such as automobile, electronics, and aviation because the production activities in these industries are decentralized [56]. In general, integrated decision-making across suppliers, shipping fleets, and

Keywords. Mathematical optimization, supply chain, cellular manufacturing, queueing theory, meta-heuristic.

* Supplementary Material is only available in electronic form at https: //www. rairo-ro. org/10. 1051/ro/2021138/olm.

1 Department of Industrial Engineering, Iran University of Science and Technology, Tehran, Iran.

2 Faculty of Industrial Engineering, Iran University of Science and Technology, Tehran, Iran.

3 School of Industrial Engineering, Iran University of Science and Technology, Narmak, Tehran 16846-13114, Iran.

* Corresponding author: mehrabad@iust.ac.ir 
manufacturer leads to customer satisfaction and can be achieved through selecting right supplier and shipping fleet to cooperate along with choosing a rational approach to production.

One of the important components of the supply chain management is choosing the right supplier. This is because the cost of raw materials constitutes a major part of the cost of finished products. At a glance in the related literature shows that supplier selection has been widely discussed [10,18,22, 25, 26,38]. Thus, supplier selection is considered one of the most important measures for manufacturers to preserve a strategic competitive position. It causes the right quality of raw materials in the right quantity to be procured at the right time and reasonable cost.

Another important component of supply chain management is selecting the right manufacturing approach. The right manufacturing approach will help respond to changing customer requests and meet the challenges of customers looking for high-quality, low-cost products. It will also cope with fluctuating demands by providing adequate speed of adjustment and sufficient production of goods. Group technology has gained worldwide acceptance as a manufacturing system philosophy due to its flexibility and adaptability [16]. Cellular manufacturing $(\mathrm{CM})$ is the application of the concepts of group technology to shop floor layout design and reconfiguration of a firm. CM provides flexibility in the manufacture of new products while effects on declining production lead time [24,60]. Manufacturers have replaced their traditional configurations like job shop and flow shop to a new one such as CM. CM leverages the positive attributes of job shop and flow shop, namely flexibility and variety, and efficiency and production volume, respectively [44,52]. Moreover, CM does not necessarily force manufacturers to invest in capital assets such as flexible manufacturing systems (FMS) to achieve flexibility. CM involves manufacturing a group of similar parts on a collection of machines or manufacturing processes [27]. The use of CM results in numerous important benefits, including reductions in material handling cost, set-up time, work-in-process inventory, throughput time, and increase in quality and scheduling simplicity [59,62]. Cell formation and cell management should be taken into account in the successful design of CM. Cell formation $(\mathrm{CF})$ as a component of $\mathrm{CM}$ involves the process of grouping parts into part families, according to the similarity in processing needs or design features, and assigning machines to machine cells [29]. Each part family should be manufactured entirely in one machine cell. In reality, parts may be manufactured in more than one cell. Cell management refers to planning issues such as scheduling and sequencing of operations. Scheduling deals to the scheduling of each part within each cell [61], while sequencing considers the order of operations behind each machine [33].

Manufacturers must focus their attention on uncertainty to improve the sustainability of their business in today's competitive marketplace. Managing uncertainty enables manufacturers to escalate their performance efficiently and effectively [58]. Uncertainties throughout supply chain can relate to demand, shipping fleet transfer time, supplier delivery time, material handling time, operating time on machines in the factory and so on. With consideration of these uncertainties, manufacturers could be quite responsive to their customers.

This research aims to make an integrated decision throughout the supply chain under uncertainty owing to the expected reduction of costs in procurement, delay, material handling, and delivery; by adopting an integrated approach to decision-making, manufacturers can hope to gain a competitive edge. However, to fulfill this purpose, the following three steps are considered simultaneously. First, the selection of suppliers for the procurement of raw materials is done based on distance, raw material price, and delivery lead time, which helps to reduce the costs of finished products and delay. Second, using CM as a manufacturing approach helps reduce delay and material handling cost. In addition, improvements in CF and cell management, reduce material handling time and resource consumption, respectively, which in turn affects delay cost. Finally, this centralized decision improves the sustainability of decision considering demand, shipping fleet transfer time, and processing time under uncertainty. Since each production plan is based on the demand of customers, these uncertainties make the integrated decision more realistic. Future demand is partially known at best and totally unknown at worst in most business environments [32]. Shipping fleet transfer time and processing time are uncertain due to traffic congestion and machine breakdown, respectively. In addition to the items mentioned, they are uncertain 
because of some unexpected events. Consideration of these uncertainties is therefore essential to obtain a reliable solution.

This paper is organized as follows: Section 2 presents a literature review on the most related studies, which are CM into supply chain management and CF with operations scheduling. Section 3 discusses problem description, model notation, model formulation, and linearization of the model. Section 4 describes the developed solution procedure. Section 5 considers computational results, including some numerical results, a sensitivity analysis, and an analysis for a spare parts manufacturer of automobiles to investigate the strength and performance of the proposed mathematical model. Finally, conclusions are given in Section 6 .

\section{Literature REVIEW}

\subsection{CM into supply chain management}

The first article considers the integration of CM and supply chain management, written by Rao and Mohanty [47]. They integrated CM and supply chain design and used some examples to prove interrelationship between $\mathrm{CM}$ and supply chain design. They also remarked, ignoring the CM in supply chain design boosts the entire supply chain cost. Schaller [51] formulated an integration of facility location, the design of CM systems within each facility, and allocation of market demands to facilities in a mixed-integer programming model. The objective function minimizes the sum of production and supply chain costs. He showed using an integrated approach, total cost was considerably declined. Benhalla et al. [8] presented the problem of integrating multi-plant CM design in supply chain design. The supply chain includes several plant facilities to produce a variety of parts and various suppliers to supply raw materials of each part. Their nonlinear model minimized the total cost of a multi-plant CM in a supply chain. Saxena and Jain [50] developed an integrated model of dynamic CM and supply chain system design. They considered several subjects, for instance, multiple markets, multi-plant locations, reconfiguration, multi-time periods, etc. The objective function minimizes the sum of costs, including machine procurement, machine maintenance overhead, machine repair, machine setup, tool consumption, machine operation, non-utilization of machines in breakdown, reconfiguration of machine installation, the reconfiguration of machine removal, part intra-cell movement, part inter-cell movement, part holding, raw material outsourcing, finished outsourcing, and external transportation. Paydar et al. [42] proposed a mixed-integer linear programming model, considering some uncertain parameters such as machine capacities and customer demands for the integration of design of $\mathrm{CF}$ and production planning, and procurement in a supply chain concurrently. The objective function minimizes the whole costs consisting of inter-cell and intra-cell movement of parts, inventory, the investment of machines, and procurement. Paydar and Saidi-Mehrabad [40] studied the integration of procurement, production and distribution planning in a bi-objective possibilistic programming model. They formulated a dynamic virtual CF problem in the production stage of the supply chain. A virtual CF problem includes a group of machines devoted to producing a part family, but machines do not have to be near each other, i.e., they can be in different places on the shop floor physically. In this model, uncertainty is due to machine capacities and customer demands. The first objective function minimized the costs of procurement, production and delivery activities and the second one maximized the grouping efficacy of finished parts in virtual cells. Aalaei and Davoudpour [1] integrated a dynamic virtual CM system and supply chain design in a bi-objective optimization model. Their model covered significant manufacturing features including multi plants and facility locations, multi-period production planning, multi-markets allocations with consideration of uncertainty in capacities of resources and demand of products. The first objective function minimized the sum of costs consisting of holding, outsourcing, fixed, maintenance and overhead of machines, and external transportation. The second one minimized the entire number of exceptional elements, parts that require at least one spare operation in another cell, and movements of workers between active plants. Paydar and Saidi-Mehrabad [41] described a mathematical model for the integration of $\mathrm{CF}$, production planning, machine layout design, and determining the quantity of raw material purchased from qualified suppliers in dynamic virtual CM systems. The objective function minimizes the sum of costs, including inter-cell material movement, raw materials, the maintenance and 
overhead of machines and inventory holding, purchase, and transportation. Aalaei and Davoudpour [2] investigated a CM system into supply chain design with worker assignment under uncertain demand. They considered significant manufacturing aspects, including multi-market allocation, multi-plant location, production planning, several product mixes, and machine and worker capacity. The objective function minimizes the entire cost of holding, intercellular movement, external transportation, machine and worker, and fixed cost for producing each part in each plant. Liu et al. [36] designed a nonlinear integer programming model for dynamic CM systems in a supply chain. They attempted to consider production planning and facility transfer by presuming multiskilled workers and multiple factories simultaneously. The objective function minimizes the sum of costs such as material, facility transfer, inventory holding, and backorder. Soolaki and Arkat [55] presented a mixed-integer linear programming model for integrating procurement, production, and distribution of products in a supply chain. Their model could make decisions in terms of suppliers' choice, the site of active plants, and the site of active distribution centers. This model could also determine the product manufacturing process, the number of machines required in each cell, and procurement in each plant. The objective function minimizes total costs comprising the costs for the manufacturing of raw materials by the suppliers, the manufacturing of products, distribution centers, the foundation of the facilities at the candidate locations, and machinery.

\subsection{CF with operations scheduling}

Some of the most related research is presented that considers CF and operations scheduling problems together are reviewed as follows. Arkat et al. [4] presented two mathematical models to investigate the design of a CM system. First, the CF and cellular layout problems were solved simultaneously to minimize the total movement costs due to optimizing cell configuration and the layout of the machines on the shop floor. Second, the cellular scheduling problem was solved based on the found solution in the first model as a job shop scheduling problem. The objective function is to minimize the total completion time of parts. They showed the influences of considering cellular scheduling on a CM system design. Pasupuleti [39] presented a methodology for the detailed scheduling of all jobs in CM systems with given part families, the number of machines in each type of machine, and machine cells. In this methodology, the processing sequences of jobs, processing and setup times, and due dates were considered along with different dispatching rules, i.e., the shortest processing time, first-come firstserved, the earliest due date, the longest processing time and least slack. The methodology allocated jobs for each type of machine in each cell, and produced the detailed schedules for each job. The considered dispatching rules were evaluated by different performance measures such as mean flow time, makespan, mean tardiness, and mean lateness. Arkat et al. [5] investigated three major decisions of CM, including CF, the layout of machines, and the scheduling of operations concurrently. They proposed a multi-objective mathematical model that first and second objective functions minimized the total transportation cost of parts and makespan, respectively. Kesen and Gungor [30] discussed the job scheduling problem with a lot-streaming strategy in virtual manufacturing cells. Each job had its processing sequences and there was a set of machines to process any operation of each job. They developed a mixed-integer linear programming formulation that considers machine assignments, sub-lot sizes, and the starting times of operations. The objective function minimizes makespan since machines were distributed throughout the facility and traveling times between each pair of machines were taken into account. Eguia et al. [15] investigated $\mathrm{CF}$ and the scheduling of part families. A mixed-integer linear programming model has been presented in which the objective function minimizes production costs such as reconfigurable machine tools between two sequential families and the under-utilization of machines' resources. Solimanpur and Elmi [54] proposed a mixed-integer linear programming model for a cell scheduling problem to minimize makespan. In this model, they considered bottleneck machines and exceptional parts, processed parts in multiple cells because duplicated machines decrease intercellular movements. Taouji Hassanpour et al. [57] explored the scheduling problem of jobs in virtual CM systems. They also assumed that there were multiple jobs with different manufacturing processing routes. The objective function minimizes the sum of two weighed objectives, including tardiness and total travelling distance. Saravanan and Karthikeyan [49] addressed a scheduling optimization problem of CM systems, which consisted of different manufacturing cells. First, the Rank Order Clustering Method was used to identify and group cells for the optimization of schedules in various types of products in 
the job shop environment. Second, an optimization procedure has been presented for the scheduling problem in machine cells. The objective function minimizes the penalty cost, i.e., due dates have not been met. Fahmy [17] presented a mixed-integer linear programming model to integrate CF, group layout, and group scheduling decision problem to design a CM system. The model considered intercellular and intracellular transportation time and sequence-dependent setup time to determine optimal CF, candidate locations for machines within cells, the distances between these locations and between cells to obtain the optimal group layout, and the schedule of parts on machines concurrently. The objective function minimizes mean flow time in the system. Halat and Bashirzadeh [21] studied the problem of operation scheduling with consideration of sequence-dependent family setup time, exceptional elements, and intercellular transportation time in CM systems simultaneously. They proposed an integer linear programming model that considered all aspects of the problem, with the minimization of makespan. Liu and Wang [34] grouped multi-functional machines and multi-skilled workers and assigned them to cells. They presented a nonlinear integer mathematical model, which simultaneously integrated CF and task scheduling with a dual-resource constrained setting. The objective function minimizes makespan. Egilmez et al. [14] studied family and job sequencing problems in CM, where splitting family into cells is allowed. Each job has a specific due date, and each family requires setup before jobs in that family process. This created a conflict between decreasing the total setup time and meeting the due dates of jobs. The objective functions minimize the number of tardy jobs and total tardiness in a multi-objective mathematical model. Rafiei et al. [45] researched into CF problem and group scheduling concurrently with consideration of sequence-dependent setups in a job shop layout. They presented a mixed-integer nonlinear program to minimize the costs of operations and both intercellular and intracellular movements simultaneously in a single-period setting. Liu et al. [35] investigated a CM system under dual-resource constrained setting with consideration of CF and task scheduling concurrently. They presented a nonlinear 0-1 integer programming to minimize inter-cell material handling costs, the fixed costs of machines and workers, and the operating costs of machines and workers by taking into consideration multi-skilled machines and workers and operation sequence. Deliktas et al. [13] proposed four nonlinear multi-objective models to handle a flexible job shop scheduling problem in a CM environment. They considered intercellular movements, intercellular transportation times, exceptional parts, sequence-dependent family setup times, and recirculation- a part may visit more than once in a machine or work center. The objective function minimizes makespan as well. Feng et al. [19] discussed a dynamic cellular scheduling problem with machine sharing, that is, a machine may belong to more than one cell, and flexible routes. Makespan and total workload are minimized by the multi-objective mathematical model. In this model, machines are assigned to different cells and the sequence of operations for each part is determined simultaneously.

Against this backdrop, this paper addresses the advantage of considering CM in the supply chain management under uncertainty. A mathematical model is presented to formulate this integrated decision. Supply chain management modeling approaches include economic, deterministic analytical, stochastic, and simulation models [46]. Moreover, uncertainty can be classified according to the three approaches: stochastic programming, fuzzy programming, and robust optimization. In this research, a stochastic supply chain management is presented along with stochastic cell formation and cellular scheduling in the production stage. The interval between two consecutive arrivals of demand, the processing time on machines, and vehicle transportation time are uncertain. Queueing theory is used to formulate the uncertainties. This theory formulates simple models incorporating randomness and using comparatively little data, while being a powerful analytical tool [37]. Moreover, a genetic algorithm is proposed due to the discreteness of decision variables to deal with the complexity of the proposed model.

According to the supply chain decision hierarchy, decisions are divided into four time horizons. Their sequence from a longer horizon to a shorter horizon includes strategic planning, tactical planning, operational planning, and operational execution planning. When moving from strategic planning to operational execution planning, the horizon of decisions is shortened [53]. Moreover, this paper uses a queueing theory approach with a steady state in modeling, and therefore the decision horizon is longer than in operational planning. Then, the decision horizon in this research is tactical planning. 
Literature is summarized to highlight the filled gap by authors in Table 1. To the best of the authors' knowledge, no three-stage supply chain has been presented in the literature along with cell formation and cellular scheduling problem in the production stage under uncertainties formulated by queueing theory. The main contributions of this paper are as follows:

(1) The problem considers CF problem, cellular scheduling problem, transportation between a manufacturer and suppliers, transportation from the manufacturer to customers, and supplier selection in one mathematical model.

(2) The processing time of each machine, the demand for parts, and the transportation time of vehicles are uncertain.

(3) Cellular scheduling problem is usually studied individually while it impacts on CF, presented in the literature review. In this research, they are formulated simultaneously.

(4) A genetic algorithm (GA) is presented to deal with the complexity of the model and solve the problem in logical time.

\section{Problem DESCRIPTION}

In this section, a nonlinear supply chain model with three stages is presented to make an integrated decision. The first stage includes transportation and procurement. In this stage, vehicles transport raw materials at different speeds. Suppliers also distributed in different geographical regions deliver raw materials with different delivery times. In the second stage, i.e. in the factory, machines are grouped into cells and parts behind machines are prioritized to be processed. In the third stage, the finished products are distributed to customers in different geographic regions. Figure 1 illustrates the problem.

In this paper, four steps are performed to meet demands and queueing systems are used in each step. The interval between two consecutive arrivals of demand is exponentially distributed, and the arrival rate is less than the service rate in each queueing system. Then, the arrival rate is equivalent to the output rate for each queueing system and the time between arrivals in the three remaining queueing systems are exponentially distributed. So, queueing theory is used to formulate each step. The first step includes the interval of the ordering time of each part by a customer to load raw materials from a supplier into the vehicle(s), using an $\mathrm{M} / \mathrm{M} / \infty$ queueing model (see Fig. 2). The demand is represented as a customer in this queueing system. It is worth noting that the loading time is ignored. The second step is from a supplier to the manufacturer, for which the $\mathrm{M} / \mathrm{M} / \infty$ queueing model is used. The raw materials of each part are considered as a customer (see Fig. 3). The third step is considered as the interval in which the raw materials receive at the factory to manufacture the finished parts. In this step, an $\mathrm{M} / \mathrm{M} / 1 / \infty / \mathrm{PR}$ queueing model is considered (see Fig. 4), where each part as a customer and each machine as a server are assumed. The last step is from the manufacturer to a customer. The queueing system of this step is similar to the second step, where finished part are instead of raw materials as a customer. Meanwhile, each vehicle is assumed to be a server in all $M / M / \infty$ queueing models.

As mentioned earlier, the transportation component in the first and third stages is assumed to be an $\mathrm{M} / \mathrm{M} / \infty$ queueing model. The first $\mathrm{M}$ stands for the inter-arrival time described by the exponential distribution, the second $\mathrm{M}$ indicates the service time defined by the exponential distribution, and $\infty$ represents the number of servers, which is infinite. The production stage is assumed to be an $\mathrm{M} / \mathrm{M} / 1 / \infty / \mathrm{PR}$ queueing model. The definition of the first three symbols is mentioned in the $M / M / \infty$ queueing model. The fourth symbol indicates that there is no limitation on the system capacity. PR, a type of queue disciplines, means that the customers with the highest priorities are selected for service before the customers with lower priorities, regardless of their arrival time in the system. There are two possible refinements in priority situations, i.e., preemption and non-preemption. In this paper, non-preemption refinement is assumed. This means that there is no pause in processing, and the highest-priority customer simply goes to the first place in the queue to wait its turn. Meanwhile, each part as a customer and each machine as a server are considered that servers should serve customers. 
TABLE 1. Summary of literature and comparison with this research.

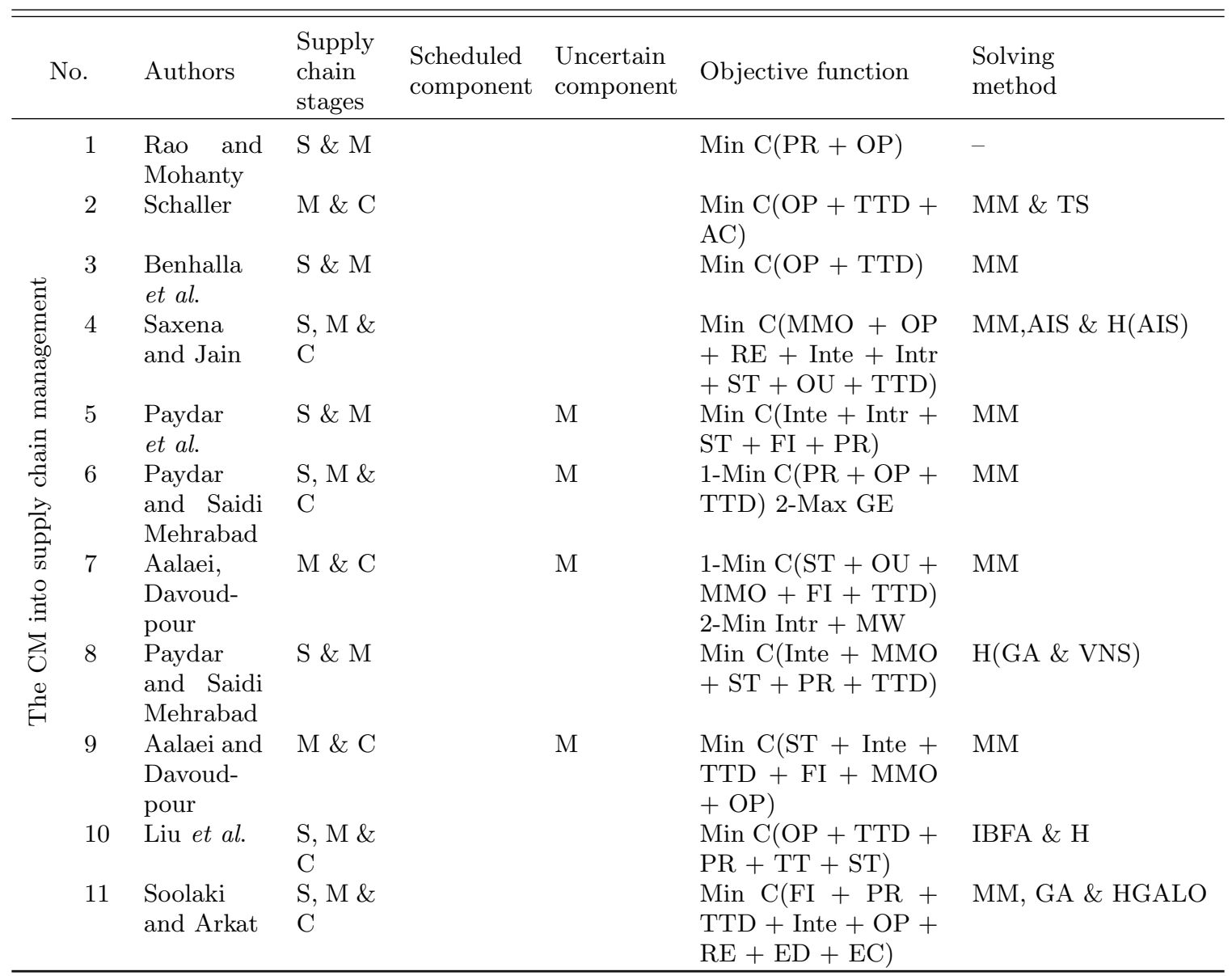

Notes. Dash (-) means two types of a problem have been investigated and stages were named based on Chopra and Meindl [11]. Supplier: S, Manufacturer: M, Customer: C, Transportation: T, and Warehouse or Distributer: W. Objectives have been numbered in multi-objective models and independent models individually. Functions used in the objectives were named such as; weighed function: $\mathrm{W}()$, cost function: $\mathrm{C}()$, and mean function: $\mathrm{M}()$. Moreover, terms in the objectives named such as; makespan: $\mathrm{C}_{\max }$, total workload: $\mathrm{TW}$, intercellular movement: Inte, intracellular movement: Intr, fixed costs: $\mathrm{C}(\mathrm{FI})$, costs of operations: $\mathrm{C}(\mathrm{OP})$, total tardiness: TT, the number of tardy jobs: NTJ, flow time: FT, tardiness of each job: TJ, total travelling distance: TTD, mean lateness: M(LA), total completion time: TCT, storage cost: C(ST), procurement cost: $\mathrm{C}(\mathrm{PR})$, amortized cost: $\mathrm{C}(\mathrm{AC})$, grouping efficacy of finished parts: GE, machine procurement cost: $\mathrm{C}(\mathrm{MP})$, machine maintenance overhead cost: $\mathrm{C}(\mathrm{MMO})$, reconfiguration: RE, outsourcing cost: $\mathrm{C}(\mathrm{OU})$, movements of the workers: MW, establishment cost of the plants: $\mathrm{C}(\mathrm{EC})$, establishment cost of distribution centers: $\mathrm{C}(\mathrm{ED})$. A hybrid algorithm was shown as $\mathrm{H}()$ which algorithms have been put inside of parentheses. Solving method were named such as; mathematical modelling: MM, genetic algorithm: GA, three-layer chromosome genetic algorithm: TCGA, discrete bacteria foraging algorithm: DBFA, simulated annealing: SA, Particle Swarm Optimization: PSO, Tabu search algorithm: TS, nested tabu search algorithm: NTS, proposed genetic algorithm: PGA, heuristic: H, artificial immune system: AIS, Variable neighborhood search: VNS, integrated bacteria foraging algorithm: IBFA, hybrid genetic ant lion optimization: HGALO. 
TABLE 1. continued.

\begin{tabular}{|c|c|c|c|c|c|c|c|}
\hline $\mathrm{N}$ & o. & Authors & $\begin{array}{l}\text { Supply } \\
\text { chain } \\
\text { stages }\end{array}$ & $\begin{array}{l}\text { Scheduled } \\
\text { component }\end{array}$ & $\begin{array}{l}\text { Uncertain } \\
\text { component }\end{array}$ & Objective function & $\begin{array}{l}\text { Solving } \\
\text { method }\end{array}$ \\
\hline \multirow{17}{*}{ 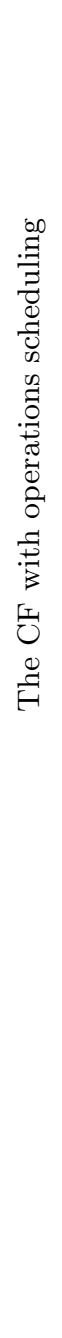 } & 12 & $\begin{array}{l}\text { Arkat } \\
\text { et al. }\end{array}$ & M & M & & $\begin{array}{l}\text { 1-Min C(Intr + Inte) } \\
\text { 2-Min TCT }\end{array}$ & GA \& MM \\
\hline & 13 & Pasupuleti & M & M & & $\begin{array}{l}\text { 1-Min } \mathrm{C}_{\max } \text { 2-Min } \\
\mathrm{M}(\mathrm{FT}) \text { 3-Min } \mathrm{M}(\mathrm{LA}) \\
\text { 4-Min M(TJ) }\end{array}$ & $\mathrm{H}$ \\
\hline & 14 & $\begin{array}{l}\text { Arkat } \\
\text { et al. }\end{array}$ & M & M & & $\begin{array}{l}\text { 1-Min } \quad \mathrm{C}(\text { Intr+Inte }) \\
\text { 2-Min } \mathrm{C}_{\max }\end{array}$ & PGA \\
\hline & 15 & $\begin{array}{l}\text { Kesen and } \\
\text { Gungor }\end{array}$ & M & M & & Min $\mathrm{C}_{\max }$ & GA \\
\hline & 16 & $\begin{array}{l}\text { Eguia } \\
\text { et al. }\end{array}$ & M & M & & Min $\mathrm{C}(\mathrm{OP})$ & $\mathrm{TS}$ \\
\hline & 17 & $\begin{array}{l}\text { Solimanpur } \\
\text { and Elmi }\end{array}$ & M & M & & Min $\mathrm{C}_{\max }$ & NTS \\
\hline & 18 & $\begin{array}{l}\text { Taouji } \\
\text { Hassanpour } \\
\text { et al. }\end{array}$ & M & M & & $\begin{array}{l}\text { Min } \mathrm{W}(\mathrm{TT}+\mathrm{Intr}+ \\
\text { Inte) }\end{array}$ & SA, GA \& MM \\
\hline & 19 & $\begin{array}{l}\text { Saravanan } \\
\text { and } \\
\text { Karthikeyan }\end{array}$ & M & M & & $\operatorname{Min} \mathrm{C}(\mathrm{TT})$ & PSO \& GA \\
\hline & 20 & Fahmy & $\mathrm{M}$ & $\mathrm{M}$ & & Min $\mathrm{M}(\mathrm{FT})$ & MM \\
\hline & 21 & $\begin{array}{l}\text { Halat and } \\
\text { Bashirzadeh }\end{array}$ & M & M & & Min $\mathrm{C}_{\max }$ & GA \& MM \\
\hline & 22 & $\begin{array}{l}\text { Liu and } \\
\text { Wang }\end{array}$ & & & & Min $\mathrm{C}_{\max }$ & $\mathrm{H}(\mathrm{SA})$ \\
\hline & 23 & $\begin{array}{l}\text { Egilmez } \\
\text { et al. }\end{array}$ & M & M & & $\begin{array}{l}\text { 1-Min } \\
\text { NTJ }\end{array}$ & MM \& GA \\
\hline & 24 & $\begin{array}{l}\text { Rafiei } \\
\text { et al. }\end{array}$ & M & M & & $\begin{array}{l}\text { Min } \\
\text { Intr })\end{array}$ & $\mathrm{H}(\mathrm{SA}, \mathrm{GA}) \& \mathrm{MM}$ \\
\hline & 25 & Liu et al. & M & M & & $\begin{array}{l}\text { Min } \mathrm{C}(\text { Inte }+\mathrm{FI}+ \\
\mathrm{OP})\end{array}$ & DBFA \\
\hline & 26 & $\begin{array}{l}\text { Deliktas } \\
\text { et al. }\end{array}$ & M & M & & Min $\mathrm{C}_{\max }$ & MM \\
\hline & 27 & Feng et al. & M & M & & $\begin{array}{l}\text { 1-Min } \mathrm{C}_{\max } \quad \text { 2-Min } \\
\text { TW }\end{array}$ & TCGA, MM \& GA \\
\hline & & $\begin{array}{l}\text { This } \\
\text { paper }\end{array}$ & $\begin{array}{l}\text { S, M \& } \\
\text { C }\end{array}$ & M & $\mathrm{T} \& \mathrm{M}$ & $\begin{array}{l}\text { Min C(TTD + PR + } \\
\text { Inte + TT) }\end{array}$ & PGA \\
\hline
\end{tabular}

The transportation component is assumed to be a queueing system where there is an unlimited service because an infinite number of vehicles are available. This assumption is rational due to third-party companies providing vehicles to factories. The number of vehicles is unlimited, whereas vehicle types are a certain number. Each vehicle type has a constant speed. The demand for part $i$ arrives at rate $\lambda_{i}$ according to a Poisson process, where one of the vehicles picks up the raw materials from a supplier at rate $\mu_{v}$. The average waiting time in the system is also $\frac{1}{\mu_{v}}$. Meanwhile, the return route from a supplier to the manufacturer and the transportation from the manufacturer to a customer are considered as the same queueing model. It should be mentioned that each supplier only produces raw materials of a certain part.

In the production stage, the $k$ th priority parts arrive at a single-channel queue according to a Poisson process with rate $\lambda_{k}(1 \leq k \leq N)$ and these parts wait within their respective priorities on a first-come, first-served basis. 
It should be noted that the smaller number of $k$ indicates a higher priority. Moreover, the distribution function of processing time for the $k$ th priority is exponential with mean $\frac{1}{\mu_{k}}$. Meanwhile, the average waiting time in the queue for the part with priority $i$ in the production stage defined as follows (for more details on the queueing system in this section, see also [20]):

$$
W_{q}^{(i)}=\frac{\sum_{k=1}^{N} \frac{\rho_{k}}{\mu_{k}}}{\left(1-\sigma_{i-1}\right)\left(1-\sigma_{i}\right)}
$$

where $\rho_{k}=\frac{\lambda_{k}}{\mu_{k}} 1 \leq k \leq N$ is called the utilization factor, $\sigma_{k}=\sum_{i=1}^{k} \rho_{i}, \sigma_{0}=0$, and the system is stationary for $\sigma_{N}<1$.

\section{Index}

$i: \quad$ Index for parts and customers $i=1,2, \ldots, P$

$j, u$ : Index for machines $j, u=1,2, \ldots, M$

$v$ : $\quad$ Index for types of vehicles $v=1,2, \ldots, V$

$s: \quad$ Index of suppliers $s=1,2, \ldots, S$

$p, r: \quad$ Index of priorities $p, r=1,2, \ldots, N$

$o: \quad$ Index of operations $o=1,2, \ldots, O_{i}$

$k$ : $\quad$ Index of cells $k=1,2, \ldots, C$

\section{Parameters}

$R_{i s}: \quad$ Delivery lead time of supplier $s$ for part $i$

$\lambda_{i}$ : $\quad$ Demand rate of part $i$ for a given planning horizon

$\mu_{j i}$ : Service rate of machine $j$ for part $i$ in a given planning horizon

$\mu_{v s}^{\prime}: \quad$ Service rate of vehicle $v$ for supplier $s$ in a given planning horizon

$\mu_{v i}^{\prime \prime}: \quad$ Service rate of vehicle $v$ for customer $i$ in a given planning horizon

$L: \quad$ A sufficiently large number

$O_{i}$ : The number of operations for part $i$

$M_{\text {max }}$ : The largest number of machines permitted for each cell

$d_{i}$ : $\quad$ The due date of part $i$

$a_{i o j}: \quad 1$ if operation $o$ of part $i$ is processed on machine $j$ and 0 otherwise

$\tau_{k k^{\prime}}$ : Inter-cell movement time of each part from cell $k$ to cell $k^{\prime}$ in order to process on required machines

$\mathrm{CO}_{v}$ : The cost of vehicle $v$ per unit time

$\mathrm{CS}_{s i}$ : The raw material price of part $i$ offered by supplier $s$

$\mathrm{CV}_{k k^{\prime}}$ : Inter-cell movement cost from cell $k$ to cell $k^{\prime}$

$\mathrm{CD}_{i}$ : The delay cost of part $i$ per unit time

\section{Decision variables}

$c_{1 i}$ : $\quad$ Mean completion time of raw materials for part $i$, the interval between the order time of part $i$ by a customer and loaded vehicle(s) ready to carry raw materials (the first component of the first stage)

$c_{2 i}$ : $\quad$ Mean procurement time of raw materials for part $i$, from the order time of part $i$ by a customer to arrival time in the manufacturer (first stage)

$c_{3 i}$ : $\quad$ Mean completion time of part $i$, from the order time of part $i$ to the production of finished part $i$

$c_{4 i}$ : $\quad$ Mean completion time of part $i$, the interval between the order time of part $i$ and the delivery of finished part $i$ to a relevant customer

$\mathrm{SU}_{s i}: \quad 1$ if part $i$ is supplied by supplier $s$ and 0 otherwise

$G_{v i}: \quad 1$ if part $i$ is picked up by vehicle $v$ from a supplier and 0 otherwise

$\mathrm{PR}_{i p}: \quad 1$ if part $i$ assigned to priority $p$ and 0 otherwise

$y_{j k}: \quad 1$ if machine $j$ assigned to cell $k$ and 0 otherwise

$G_{v i}^{\prime}$ : $\quad 1$ if part $i$ is transported by vehicle $v$ from the manufacturer to customer $i$ and 0 otherwise 


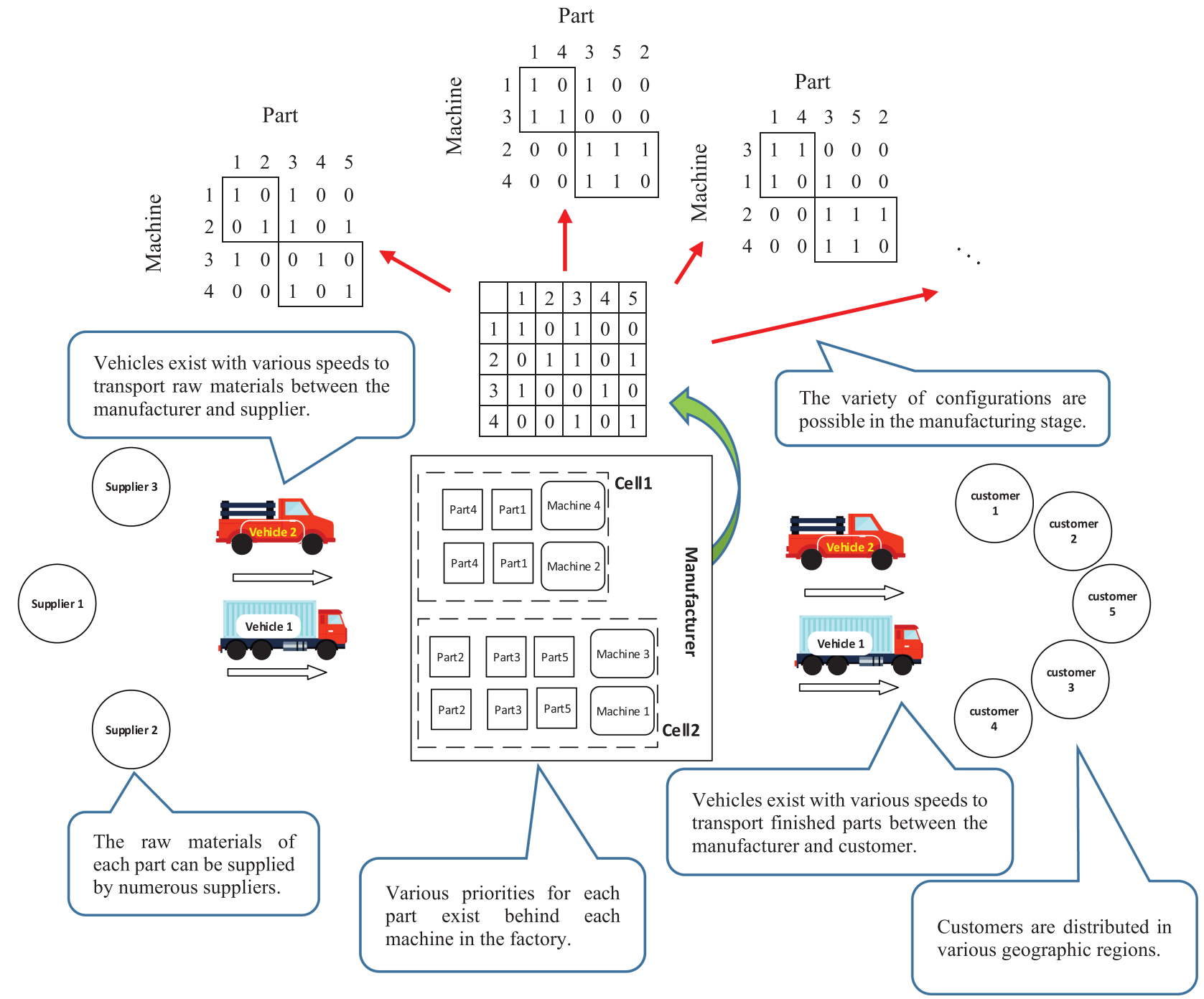

FIGURE 1. Illustration of the proposed problem.

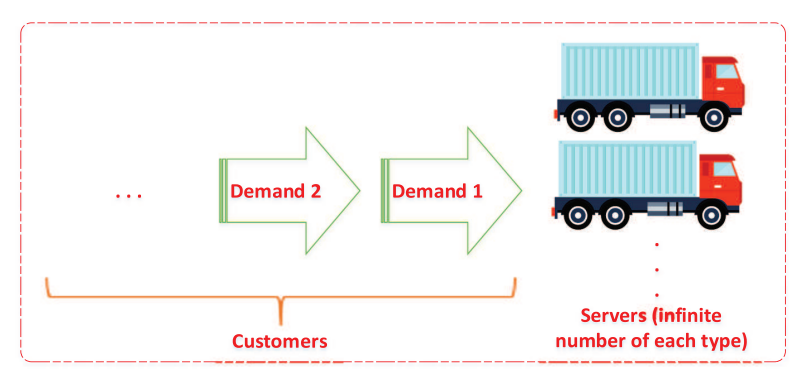

Figure 2. Queueing system for the first step. 


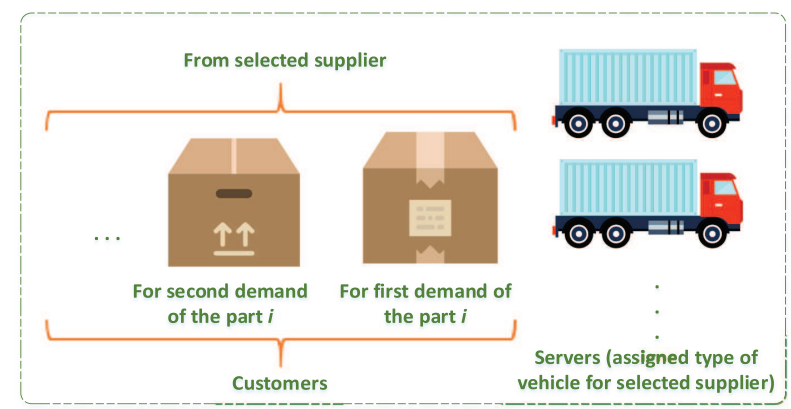

FIGURE 3. Queueing system for the second step.

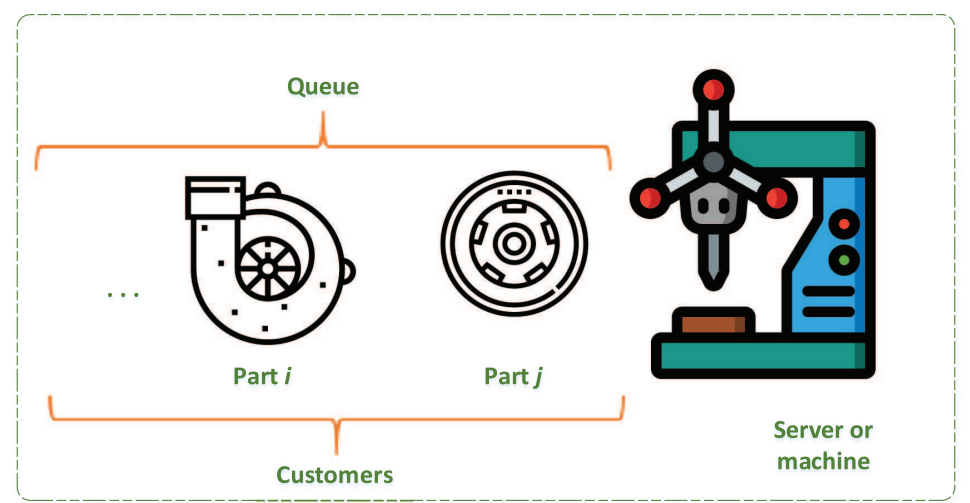

FiguRE 4. Queueing system for the third step.

\subsection{Model formulation}

The queueing system at the manufacturer must be stable, i.e., the service rate has to be necessarily larger than the arrival rate. Therefore, the amounts of used parameters in the mathematical model consider the stability condition of queueing system related to the manufacturer. The stabilizing equation (3.2) is elaborated in this subsection. The following equation avoids the infinite queue length behind each machine:

$$
\sum_{i=1}^{P} \frac{\lambda_{i} \sum_{o=1}^{O_{i}} a_{i o j}}{\mu_{j i}}<1 \quad \forall j .
$$

The mathematical model is formulated as below:

$$
\begin{aligned}
\operatorname{Min} Z= & \sum_{i=1}^{P} \sum_{v=1}^{V}\left(\mathrm{CO}_{v} \times G_{v i} \times c_{2 i}\right)+\sum_{s=1}^{S} \sum_{i=1}^{P}\left(\mathrm{CS}_{s i} \times \mathrm{SU}_{s i}\right) \\
& +\sum_{i=1}^{P} \sum_{\substack{j=1 \\
j \neq u}}^{M} \sum_{u=1}^{M} \sum_{\substack { k=1 \\
\begin{subarray}{c}{k^{\prime}=1 \\
k \neq k^{\prime}{ k = 1 \\
\begin{subarray} { c } { k ^ { \prime } = 1 \\
k \neq k ^ { \prime } } }\end{subarray}}^{C} \sum_{o=1}\left(\mathrm{CV}_{k k^{\prime}}\left(\left(a_{i o j} y_{j k}\right)\left(a_{i(o+1) u} y_{u k^{\prime}}\right)\right)\right) \\
& +\sum_{v=1}^{V} \sum_{i=1}^{P}\left(\mathrm{CO}_{v} \times G_{v i}^{\prime} \times\left(c_{4 i}-c_{3 i}\right)\right)+\sum_{i=1}^{P}\left(\mathrm{CD}_{i} \times \max \left\{0, c_{4 i}-d_{i}\right\}\right)
\end{aligned}
$$




$$
\begin{array}{lc}
\text { s.t. } & \sum_{s=1}^{S} \mathrm{SU}_{s i}=1 \\
\mathrm{SU}_{s i} \leq L \times R_{i s} & \forall i \\
\sum_{v=1}^{V} G_{v i}=1 & \forall s, i \\
c_{1 i} \geq \sum_{s=1}^{S} \sum_{v=1}^{V} \frac{1}{\mu_{v s}^{\prime}} \mathrm{SU}_{s i} G_{v i} & \forall i \\
c_{1 i} \geq \sum_{s=1}^{S} R_{i s} \mathrm{SU}_{s i} & \forall i \\
c_{2 i} \geq c_{1 i}+\sum_{s=1}^{S} \sum_{v=1}^{V} \frac{1}{\mu_{v s}^{\prime}} G_{v i} \mathrm{SU}_{s i} & \forall i \\
\sum_{i=1}^{P} \mathrm{PR}_{i p}=1 & \forall i \\
\sum_{p=1}^{N} \mathrm{PR}_{i p}=1 & \forall p \\
\sum_{k=1}^{C} y_{j k}=1 & \forall i \\
\sum_{j=1}^{M} y_{j k} \leq M_{\max } & \forall j
\end{array}
$$

$$
\begin{aligned}
& c_{3 i} \geq c_{2 i} \\
& +\sum_{j=1}^{M} \sum_{p=1}^{N}\left(\frac{\sum_{i=1}^{p} \frac{\lambda_{i} \sum_{o=1}^{O_{i} a_{i o j}}}{\left(\mu_{j i}^{2}\right)^{2}}}{\left(1-\sum_{i=1}^{P}\left[\frac{\lambda_{i} \sum_{o=1}^{O_{i}} a_{i o j}}{\mu_{j i}}\right]\left(\sum_{r=1}^{(p-1)} \mathrm{PR}_{i r}\right)\right)\left(1-\sum_{i=1}^{P}\left[\frac{\lambda_{i} \sum_{o=1}^{O_{i}} a_{i o j}}{\mu_{j i}}\right]\left(\sum_{r=1}^{p} \mathrm{PR}_{i r}\right)\right)}\right. \\
& \left.+\sum_{i=1}^{P} \frac{\mathrm{PR}_{i p} \sum_{o=1}^{O_{i}} a_{i o j}}{\mu_{j i}}\right) \mathrm{PR}_{i p}+\sum_{j=1}^{M} \sum_{\substack{u=1 \\
u \neq j}}^{M} \sum_{\substack { k=1 \\
\begin{subarray}{c}{k^{\prime}=1 \\
k \neq k^{\prime}{ k = 1 \\
\begin{subarray} { c } { k ^ { \prime } = 1 \\
k \neq k ^ { \prime } } }\end{subarray}}^{C} \sum_{o=1}^{\left(O_{i}-1\right)} \tau_{k k^{\prime}}\left(a_{i o j} y_{j k}\right)\left(a_{i(o+1) u} y_{u k^{\prime}}\right) \quad \forall i \\
& \sum_{v=1}^{V} G_{v i}^{\prime}=1 \\
& \forall i \\
& c_{4 i} \geq c_{3 i}+\sum_{v=1}^{V} \frac{1}{\mu_{v i}^{\prime \prime}} G_{v i}^{\prime} \quad \forall i \\
& \mathrm{SU}_{s i}, G_{v i}, G_{v i}^{\prime}, \mathrm{PR}_{i p}, y_{j k} \in\{0,1\}, c_{1 i}, c_{2 i}, c_{3 i}, c_{4 i} \geq 0 \quad \forall s, i, v, p, j, k, o .
\end{aligned}
$$

Objective function (3.3) minimizes the total cost, including the procurement and its transfer cost to the manufacturer, inter-cell movement cost, the transfer cost of finished parts, and the delay cost of finished parts. 
Inter-cell movement costs minimize the movement of parts between cells. It leads to processing more parts within each cell. Constraint (3.4) guarantees that each part must be assigned to one supplier. Constraint (3.5) causes one supplier to be selected among suppliers with the production capability of raw materials for part $i$ (i.e., $R_{i s}>0$ ). Constraint (3.6) ensures that each part is assigned to one vehicle type. As mentioned above, the waiting time in the system for the $\mathrm{M} / \mathrm{M} / \infty$ queueing system is the mean service time. Then, constraint (3.7) shows that the mean completion time of raw materials for each part in a relevant supplier (i.e., $\left.c_{1 i}\right)$ is at least equal to the mean service time of the vehicle. Constraint (3.8) makes sure that the mean completion time of raw materials in a supplier for each part is bigger than the delivery lead time of the same supplier. Constraint (3.9) guarantees that the mean procurement time of raw materials is larger than the mean completion time of raw materials in a supplier plus mean transportation time from the same supplier to the manufacturer for each part. Constraints (3.10) and (3.11) assign each priority to one part. Constraint (3.12) makes sure that each machine is assigned only to one cell. Constraint (3.13) ensures that the maximum number of machines does not exceed the certain amount $M_{\max }$. Constraint (3.14) specifies the mean completion time of part $i$ from the order time of part $i$ to the production of finished part $i$ (i.e., $c_{3 i}$ ), which is the sum of three terms. They are the mean procurement time of raw materials for part $i\left(i . e ., c_{2 i}\right)$, the mean waiting time of part $i$ in the manufacturing stage, and the inter-cell movement time of part $i$. The mean waiting time of each part in the manufacturing stage comprises two terms. The first term in parentheses indicates the mean waiting time of the $p$-priority part in the queue behind machine $j$. Term $\left[\frac{\lambda_{i} \sum_{o=1}^{O_{i}} a_{i o j}}{\mu_{j i}}\right]$ represents the utilization factor of machine $j$ to process part $i$, where term $\sum_{o=1}^{O_{i}} a_{i o j}$ indicates the number of operations of part $i$ on machine $j$. The utilization factor of machine $j$ to process the part with priority $r$ is obtained via multiplying term $\left[\frac{\lambda_{i} \sum_{o=1}^{O_{i}} a_{i o j}}{\mu_{j i}}\right]$ by $\mathrm{PR}_{i r}$ and the result is $\sum_{i=1}^{P}\left(\left[\frac{\lambda_{i} \sum_{o=1}^{O_{i}} a_{i o j}}{\mu_{j i}}\right] \times \mathrm{PR}_{i r}\right)$. Therefore, term $\sigma_{p-1}$ in equation (3.1) is equal to $\sum_{r=1}^{(p-1)}\left(\sum_{i=1}^{P}\left(\left[\frac{\lambda_{i} \sum_{o=1}^{O_{i}} a_{i o j}}{\mu_{j i}}\right] \times \mathrm{PR}_{i r}\right)\right)$, and is rewritten to term $\sum_{i=1}^{P}\left[\frac{\lambda_{i} \sum_{o=1}^{O_{i}} a_{i o j}}{\mu_{j i}}\right]\left(\sum_{r=1}^{(p-1)} \mathrm{PR}_{i r}\right)$ in constraint (3.14). The second term in parentheses of the mean waiting time of each part in the manufacturing stage is the mean processing time for $p$-priority part on machine $j$. Finally, the sum of the two terms in parentheses is multiplied by $\mathrm{PR}_{i p}$ to obtain the mean waiting time of part $i$ to be processed on machine $j$. The third term of constraint (3.14) means that when the next operation of a certain part is processed in another cell, it causes the inter-cell movement of the same part. It should be noted that intra-cell movement time is neglected. Constraint (3.15) ensures that each part is assigned to one vehicle type to transport the final part from the manufacturer to a respective customer. Constraint (3.16) indicates that the sum of completion time from the order time until the production of finished part $\left(i . e ., c_{3 i}\right)$ and mean transportation time from the manufacturer to a respective customer will not exceed the mean completion time from the order time until the delivery of finished part (i.e., $c_{4 i}$ ). Constraint (3.17) defines the ranges of the decision variables. Finally, the utilization factor of each machine in the manufacturing stage must be less than 1 to avoid the instability of the queueing system. The utilization factor of machine $j, \rho_{j}$, is equal to the arrival rate divided by the service rate. Moreover, the part arrival rate of machine $j$ is $\sum_{i} \lambda_{i}$, because the part arrival time to be processed on machine $j$ is equal to the most minimization of the arrival time of the parts that need to be processed on machine $j$. The inter-arrival time between two consecutive parts has an exponential distribution, then the most minimization of the part arrival time to be processed has an exponential distribution with parameter $\sum_{i} \lambda_{i}$. Finally, $\rho_{j}=\sum_{k=1}^{C} \frac{\sum_{i=1}^{P} \sum_{o=1}^{O_{i}} \lambda_{i} a_{i o j} y_{j k}}{\mu_{j i}} \forall j$ is rewritten using equation (3.12), $\sum_{k=1}^{C} y_{j k}=1 \forall j$, to find equation (3.2).

\subsection{Linearization}

The proposed model is a nonlinear mathematical model. Hence, three steps are used to linearize the proposed model. In the first step, objective function (3.3) is linearized with defining four new variables $G c_{v i} \geq 0, t y_{j u k k^{\prime}} \in$ $\{0,1\}, G c p_{v i} \geq 0$, and $\mathrm{CDI}_{i} \geq 0$, which are respectively equal to $G_{v i} \times c_{2 i}, y_{j k} \times y_{u k^{\prime}}, G_{v i}^{\prime} \times\left(c_{4 i}-c_{3 i}\right)$, and 
$\max _{i}\left\{0, c_{4 i}-d_{i}\right\}$. The following constraints should be added to the proposed model for the linearization of the first term of objective function (3.3):

$$
\begin{array}{ll}
G c_{v i} \leq L \times G_{v i} & \forall v, i \\
G c_{v i} \leq c_{2 i} & \forall v, i \\
G c_{v i} \geq c_{2 i}-\left(1-G_{v i}\right) \times L & \forall v, i .
\end{array}
$$

The third term of objective function (3.3) and the third term of constraint (3.14) are linearized by adding the following constraints:

$$
\begin{aligned}
& t y_{j u k k^{\prime}}-y_{j k}-y_{u k^{\prime}}+1.5 \geq 0 \quad \forall u, j, k, k^{\prime}, u \neq j, k \neq k^{\prime} \\
& 1.5 t y_{j u k k^{\prime}}-y_{j k}-y_{u k^{\prime}} \leq 0 \quad \forall u, j, k, k^{\prime}, u \neq j, k \neq k^{\prime} .
\end{aligned}
$$

The following constraints should be added to the proposed model to linearize the fourth term of objective function (3.3) considering $c_{4 i}-c_{3 i}>0$ :

$$
\begin{array}{ll}
G c p_{v i} \leq L \times G_{v i}^{\prime} & \forall v, i \\
G_{c p} \leq\left(c_{4 i}-c_{3 i}\right) & \forall v, i \\
G c p_{v i} \geq\left(c_{4 i}-c_{3 i}\right)-\left(1-G_{v i}^{\prime}\right) \times L & \forall v, i .
\end{array}
$$

The last term of objective function (3.3) is linearized by adding two following constraints:

$$
\begin{array}{ll}
\mathrm{CDI}_{i} \geq 0 & \forall i \\
\mathrm{CDI}_{i} \geq c_{4 i}-d_{i} & \forall i .
\end{array}
$$

In the second step, constraints (3.7) and (3.9) are linearized by defining a new binary variable SUG $G_{s v i}$, which is equal to $\mathrm{SU}_{s i} \times G_{v i} \forall s, v, i$. Two following constraints are also added to the proposed model:

$$
\begin{array}{rlr}
\mathrm{SU}_{s v i}-\mathrm{SU}_{s i}-G_{v i}+1.5 & \geq 0 & \forall s, v, i \\
1.5 \mathrm{SU} G_{s v i}-\mathrm{SU}_{s i}-G_{v i} & \leq 0 & \forall s, v, i .
\end{array}
$$

In the third step, constraint (3.14) is linearized through considering new variables. First, the mean waiting time of the $p$-priority part in the queue behind the machine $j$ is linearized by introducing variable $\mathrm{WT}_{j p} \geq 0$ which is equal to:

$$
\mathrm{WT}_{j p}=\frac{\sum_{i=1}^{P} \frac{\lambda_{i} \sum_{o=1}^{O_{i}} a_{i o j}}{\left(\mu_{j i}\right)^{2}}}{\left(1-\sum_{i=1}^{P}\left[\frac{\lambda_{i} \sum_{o=1}^{O_{i}} a_{i o j}}{\mu_{j i}}\right]\left(\sum_{r=1}^{(p-1)} \mathrm{PR}_{i r}\right)\right)\left(1-\sum_{i=1}^{P}\left[\frac{\lambda_{i} \sum_{o=1}^{O_{i}} a_{i o j}}{\mu_{j i}}\right]\left(\sum_{r=1}^{p} \mathrm{PR}_{i r}\right)\right)} \quad \forall j, p .
$$

The new auxiliary variables $Q_{j p i r} \geq 0, \operatorname{DPR}_{i(q q)(t t)} \in\{0,1\}, \operatorname{WPR}_{j p i(q q)(t t)} \geq 0, \operatorname{TPR}_{q t r^{\prime} r^{\prime \prime}} \in\{0,1\}$, $\mathrm{WTPR}_{j p q t r^{\prime} r^{\prime \prime}} \geq 0, \mathrm{WR}_{j p i} \geq 0, \mathrm{SPR}_{i^{\prime} i^{\prime \prime} p r} \in\{0,1\}$, and $\mathrm{WSPR}_{j p i^{\prime} i^{\prime \prime} r} \geq 0$ are presented to linearize equation (3.30). Moreover, the relevant constraints should be added to the proposed model, which are presented below.

$$
\begin{aligned}
\mathrm{WT}_{j p} & -2 \sum_{i=1}^{P}\left(\left(\frac{\lambda_{i} \sum_{o=1}^{O_{i}} a_{i o j}}{\mu_{j i}}\right)\left(\sum_{r=1}^{p} Q_{j p i r}\right)\right) \\
& +\sum_{i=1}^{P}\left(\left(\frac{\lambda_{i} \sum_{o=1}^{O_{i}} a_{i o j}}{\mu_{j i}}\right)^{2}\left(\sum_{r=1}^{p} Q_{j p i r}+2 \sum_{t t=1}^{p} \sum_{q q=1}^{t t-1} \mathrm{WPR}_{j p i}(q q)(t t)\right)\right)
\end{aligned}
$$




$$
\begin{aligned}
& +2 \sum_{t=1}^{P} \sum_{q=1}^{t-1}\left(\left(\frac{\lambda_{q} \sum_{o=1}^{O_{i}} a_{q o j}}{\mu_{j q}}\right)\left(\frac{\lambda_{t} \sum_{o=1}^{O_{i}} a_{t o j}}{\mu_{j t}}\right) \sum_{r^{\prime}=1}^{P} \sum_{r^{\prime \prime}=1}^{P} \mathrm{WTPR}_{j p q t r^{\prime} r^{\prime \prime}}\right) \\
& +\sum_{i=1}^{P}\left(\frac{\lambda_{i} \sum_{o=1}^{O_{i}} a_{i o j}}{\mu_{j i}}\right) \mathrm{WR}_{j p i}-\sum_{i^{\prime}=1}^{P} \sum_{i^{\prime \prime}=1}^{P}\left(\left(\frac{\lambda_{i^{\prime}} \sum_{o=1}^{O_{i}} a_{i^{\prime} o j}}{\mu_{j i^{\prime}}}\right)\left(\frac{\lambda_{i^{\prime \prime}} \sum_{o=1}^{O_{i}} a_{i^{\prime \prime} o j}}{\mu_{j i^{\prime \prime}}}\right) \sum_{r=1}^{p} \mathrm{WSPR}_{j p i^{\prime} i^{\prime \prime} r}\right) \\
& =\sum_{i=1}^{P} \frac{\lambda_{i} \sum_{o=1}^{O_{i}} a_{i o j}}{\left(\mu_{j i}\right)^{2}} \quad \forall j, p
\end{aligned}
$$

$Q_{j p i r}=\mathrm{WT}_{j p} \times \mathrm{PR}_{i r}$

$Q_{\text {jpir }} \leq L \times \mathrm{PR}_{i r}$

$Q_{\text {jpir }} \leq \mathrm{WT}_{j p}$

$Q_{j p i r} \geq \mathrm{WT}_{j p}-\left(1-\mathrm{PR}_{i r}\right) \times L$

$\mathrm{DPR}_{i(q q)(t t)}=\mathrm{PR}_{i(q q)} \times \mathrm{PR}_{i(t t)}$

$\mathrm{DPR}_{i(q q)(t t)}-\mathrm{PR}_{i(q q)}-\mathrm{PR}_{i(t t)}+1.5 \geq 0$

$1.5 \mathrm{DPR}_{i(q q)(t t)}-\mathrm{PR}_{i(q q)}-\mathrm{PR}_{i(t t)} \leq 0$

$\mathrm{WPR}_{j p i(q q)(t t)}=\mathrm{WT}_{j p} \times \mathrm{DPR}_{i(q q)(t t)}$

$\mathrm{WPR}_{j p i(q q)(t t)} \leq L \times \mathrm{DPR}_{i(q q)(t t)}$

$\mathrm{WPR}_{j p i(q q)(t t)} \leq \mathrm{WT}_{j p}$

$\mathrm{WPR}_{j p i(q q)(t t)} \geq \mathrm{WT}_{j p}-\left(1-\mathrm{DPR}_{i(q q)(t t)}\right) \times L$

$\mathrm{TPR}_{q t r^{\prime} r^{\prime \prime}}=\mathrm{PR}_{q r^{\prime}} \times \mathrm{PR}_{t r^{\prime \prime}}$

$\mathrm{TPR}_{q t r^{\prime} r^{\prime \prime}}=\mathrm{PR}_{q r^{\prime}}-\mathrm{PR}_{t r^{\prime \prime}}+1.5 \geq 0$

$1.5 \mathrm{TPR}_{q t r^{\prime} r^{\prime \prime}}-\mathrm{PR}_{q r^{\prime}}-\mathrm{PR}_{t r^{\prime \prime}} \leq 0$

$\mathrm{WTPR}_{j p q t r^{\prime} r^{\prime \prime}}=\mathrm{WT}_{j p} \times \mathrm{TPR}_{q t r^{\prime}} r^{\prime \prime}$

$\mathrm{WTPR}_{j p q t r^{\prime} r^{\prime \prime}} \leq L \times \mathrm{TPR}_{q t r^{\prime} r^{\prime \prime}}$

$\mathrm{WTPR}_{j p q t r^{\prime} r^{\prime \prime}} \leq \mathrm{WT}_{j p}$

$\mathrm{WTPR}_{j p q t r^{\prime} r^{\prime \prime}} \geq \mathrm{WT}_{j p}-\left(1-\mathrm{TPR}_{q t r^{\prime} r^{\prime \prime}}\right) \times L$

$\mathrm{WR}_{j p i}=\mathrm{WT}_{j p} \times \mathrm{PR}_{i p}$

$\mathrm{WR}_{j p i} \leq L \times \mathrm{PR}_{i p}$

$\mathrm{WR}_{j p i} \leq \mathrm{WT}_{j p}$

$\mathrm{WR}_{j p i} \leq \mathrm{WT}_{j p}-\left(1-\mathrm{PR}_{i p}\right) \times L$

$\mathrm{SPR}_{i^{\prime} i^{\prime \prime} p r}=\mathrm{PR}_{i^{\prime} p} \times \mathrm{PR}_{i^{\prime \prime} r}$

$\mathrm{SPR}_{i^{\prime} i^{\prime \prime} p r}-\mathrm{PR}_{i^{\prime} p}-\mathrm{PR}_{i^{\prime \prime} r}+1.5 \geq 0$

$1.5 \mathrm{SPR}_{i^{\prime} i^{\prime \prime} p r}-\mathrm{PR}_{i^{\prime} p}-\mathrm{PR}_{i^{\prime \prime} r} \leq 0$

$\mathrm{WSPR}_{j p i^{\prime} i^{\prime \prime} r}=\mathrm{WT}_{j, p} \times \mathrm{SPR}_{i^{\prime} i^{\prime \prime} p r}$

$\mathrm{WSPR}_{j p i^{\prime} i^{\prime \prime} r} \leq L \times \mathrm{SPR}_{i^{\prime} i^{\prime \prime} p r}$

$\mathrm{WSPR}_{j p i^{\prime} i^{\prime \prime} r} \leq \mathrm{WT}_{j p}$

$\mathrm{WSPR}_{j p i^{\prime} i^{\prime \prime} r} \geq \mathrm{WT}_{j p}-\left(1-\mathrm{SPR}_{i^{\prime} i^{\prime \prime} p r}\right) \times L$ $\forall j, p, i ; r=1,2, \ldots, p$

$\forall j, p, i, r$

$\forall j, p, i, r$

$\forall j, p, i, r$

$\forall i ; q q=1,2, \ldots,(t t-1) ; t t=1,2, \ldots, p$

$\forall i ; q q=1,2, \ldots,(t t-1) ; t t=1,2, \ldots, p$

$\forall i ; q q=1,2, \ldots,(t t-1) ; t t=1,2, \ldots, p$

$\forall j, p, i ; q q=1,2, \ldots,(t t-1) ; t t=1,2, \ldots, p$

$\forall i ; q q=1,2, \ldots,(t t-1) ; t t=1,2, \ldots, p$

$\forall i ; q q=1,2, \ldots,(t t-1) ; t t=1,2, \ldots, p$

$\forall i ; q q=1,2, \ldots,(t t-1) ; t t=1,2, \ldots, p$

$\forall r^{\prime}, r^{\prime \prime} ; t=1,2, \ldots, P ; q=1,2, \ldots,(t-1)$

$\forall r^{\prime}, r^{\prime \prime} ; t=1,2, \ldots, P ; q=1,2, \ldots,(t-1)$

$\forall r^{\prime}, r^{\prime \prime} ; t=1,2, \ldots, P ; q=1,2, \ldots,(t-1)$

$\forall r^{\prime}, r=1,2, \ldots, p ; \forall t=1,2, \ldots, P ;$

$\forall q=1,2, \ldots,(t-1) ; \forall q, p$

$\forall j ; p ; q ; t ; r^{\prime} ; r^{\prime \prime}$

$\forall j ; p ; q ; t ; r^{\prime} ; r^{\prime \prime}$

$\forall j ; p ; q ; t ; r^{\prime} ; r^{\prime \prime}$

$\forall j ; p ; i$

$\forall j ; p ; i$

$\forall j ; p ; i$

$\forall j ; p ; i$

$\forall i^{\prime}, i^{\prime \prime}=1,2, \ldots, P ; \forall p ; \forall r=1,2, \ldots, p$

$\forall i^{\prime}, i^{\prime \prime}=1,2, \ldots, P ; \forall p ; \forall r=1,2, \ldots, p$

$\forall i^{\prime}, i^{\prime \prime}=1,2, \ldots, P ; \forall p ; \forall r=1,2, \ldots, p$

$\forall j ; p ; \forall i^{\prime}, i^{\prime \prime}=1,2, \ldots, P$

$\forall j ; p ; \forall i^{\prime}, i^{\prime \prime}=1,2, \ldots, P$

$\forall j ; p ; \forall i^{\prime}, i^{\prime \prime}=1,2, \ldots, P$

$\forall j ; p ; \forall i^{\prime}, i^{\prime \prime}=1,2, \ldots, P$.

Second, the mean processing time for part $i$ on machine $j$ is obtained via multiplying the mean processing time for the $p$-priority part on machine $j$ by $\mathrm{PR}_{i p}$. It is linearized by defining a new variable $\mathrm{MPR}_{i^{\prime} i p} \in\{0,1\}$, which 
is equal to $\mathrm{PR}_{i^{\prime} p} \times \mathrm{PR}_{i p}$ and adding the following constraints in the proposed model.

$$
\begin{aligned}
\mathrm{MPR}_{i^{\prime} i p}-\mathrm{PR}_{i^{\prime} p}-\mathrm{PR}_{i p}+1.5 & \geq 0 \\
1.5 \mathrm{MPR}_{i^{\prime} i p}-\mathrm{PR}_{i^{\prime} p}-\mathrm{PR}_{i p} \leq 0 & \forall i, i^{\prime}=1,2, \ldots, P ; \forall p=1,2, \ldots, N ; \\
& \forall i, i^{\prime}=1,2, \ldots, P ; \forall p=1,2, \ldots, N .
\end{aligned}
$$

Finally, the following linearized version is used instead of constraint (3.14).

$$
c_{3 i} \geq c_{2 i}+\sum_{j=1}^{M} \sum_{p=1}^{N}\left(\mathrm{WR}_{j p i}+\sum_{i^{\prime}=1}^{P} \frac{\mathrm{MPR}_{i^{\prime} i p} \sum_{o=1}^{O_{i}} a_{i^{\prime} o j}}{\mu_{j i^{\prime}}}\right)+\sum_{j=1}^{M} \sum_{\substack{u=1 \\ u \neq j}}^{M} \sum_{\substack{k=1 \\ k^{\prime}=1}}^{C} \sum_{\substack{k^{\prime}=k^{\prime} \\ k=1}}^{\left(O_{i}-1\right)} \tau_{k k^{\prime}} a_{i o j} a_{i(o+1) u} t y_{j u k k^{\prime}} \quad \forall i .
$$

\section{SOLUTION PROCEDURE}

The NP-hardness of the CF problem has been shown by some researchers [6,7,31]. Therefore, our more general problem is also NP-hard. Moreover, the discreteness of the decision variables convinces us to choose the genetic algorithm among meta-heuristic algorithms to solve the stated problem.

GAs are based on population and random search that follow the basic laws of biological evolution, natural choice, and gene recombination [43]. GA begins from a pool of usually randomly generated chromosomes (i.e., solutions). A fitness function value selects between chromosomes. Crossover and mutation are used to generate a new generation for each new iteration of the algorithm. The outcome is also a population of chromosomes because a population of chromosomes is processed in each iteration of GA. If an optimization problem has a global optimum, then all chromosomes can be expected to converge to it [28]. An overview of our framework is illustrated in Figure 5.

The first step is to define the structure for a solution or chromosome. In this paper, a solution representation has the form of a matrix with 1 row and $4 \times P+M$ ( $M$ is the number of machines and $P$ is the number of parts) columns. The structure of the solution matrix is shown in Figure 6. The first $P$ arrays of the matrix are filled with the assigned vehicle types to pick up the raw materials from a supplier to the manufacturer. The second $P$ arrays of the matrix select the suppliers that produce the raw materials of parts. The third segment, i.e., $M$ positions of the matrix is filled with the assigned cell number so that each machine is in only one cell. The fourth segment, i.e., $P$ arrays of the matrix, is the assigned vehicle types to transport from the manufacturer to a customer. The last $P$ arrays of the matrix are the priorities of parts, where each part is assigned to only one priority.

\subsection{Population initialization}

A set of feasible solutions is generated as an initial population. The steps of initial solutions are shown in Figure 7.

\subsection{Fitness function}

A fitness function measures chromosomes in a population. Some or all of the better chromosomes are selected for the next iteration generation. In this study, the objective function of the proposed model is the fitness function. It should be noted, the new generation is called offspring or children in the GA and each chromosome respects all the constraints of the proposed model.

\subsection{Selection method}

Tournament selection is a selection strategy used in the proposed algorithm. It selects suitable chromosomes from the current generation to be used in the next generation. First, a certain number of chromosomes is randomly selected. Second, the selection strategy runs a tournament between them based on a fitness function. Finally, the best one is selected to be used in the crossover operator. When the tournament size is large, chromosomes with weak fitness functions may compete with stronger ones. 


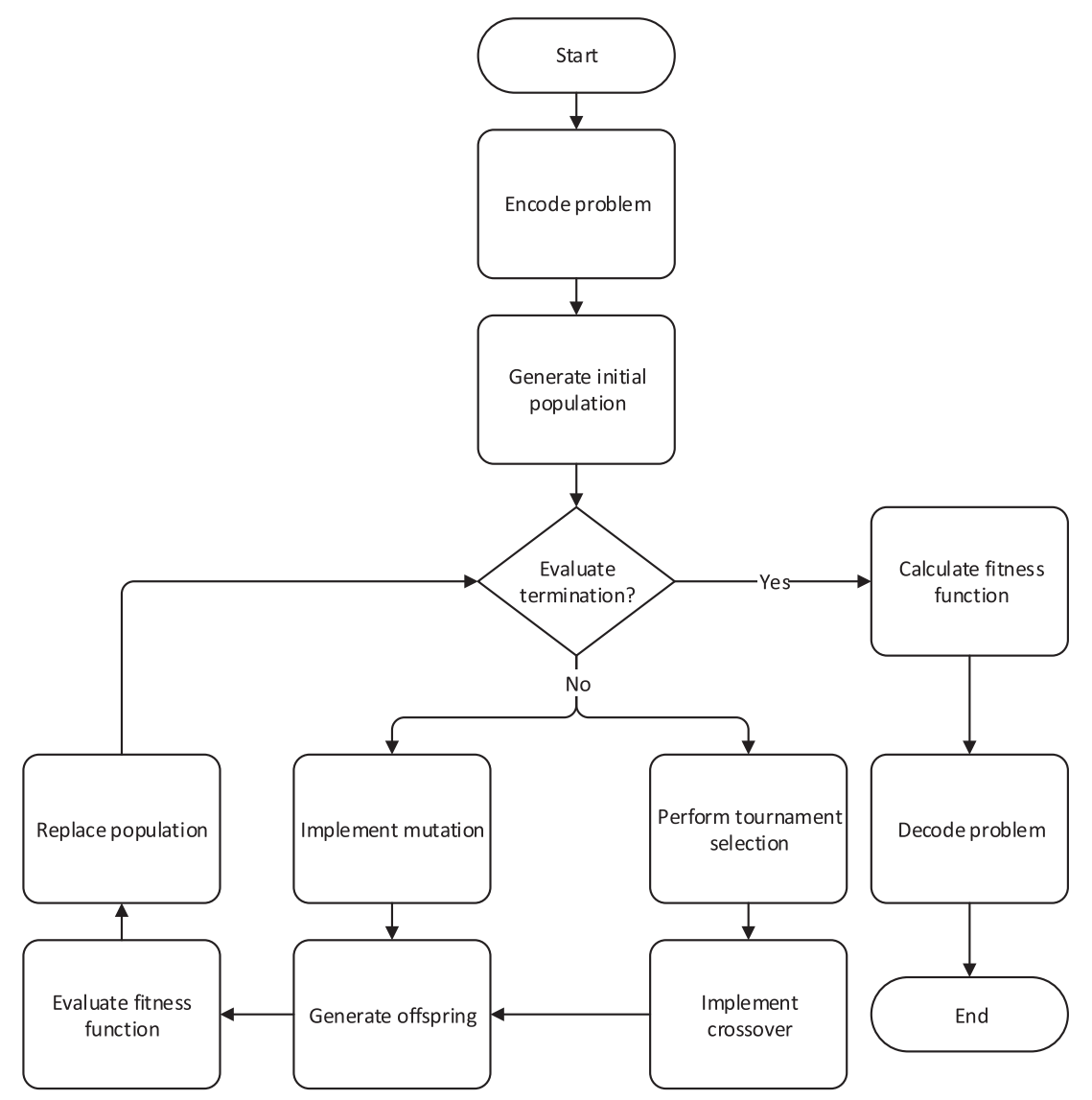

FiguRE 5. The proposed genetic algorithm framework.

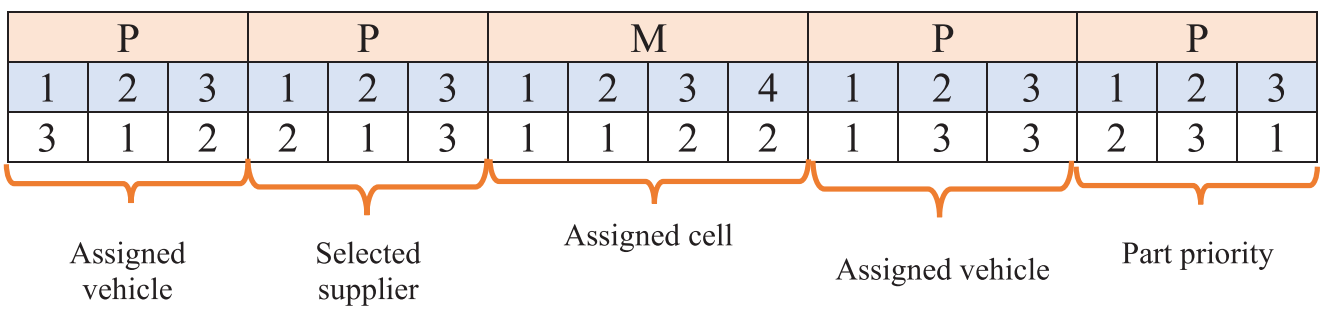

FiguRE 6. A sample solution representation.

\subsection{Crossover operator}

A crossover operator replaces the data from two parents and generates children from them. These children inherit some segments from their parents. In this paper, the one-point crossover is chosen among crossover mechanisms to generate children from the result of the tournament selection. An example is shown in Figure 8 to clarify the one-point crossover mechanism. It should be noted, the last segment of the chromosome, the priorities of parts, is not considered for the crossover mechanism. In the one-point crossover, genes of parents are replaced with each other to generate children from both parents. 
Step 1: Set $r=1$ (population index) and identify the population of chromosomes $\rightarrow$ pop;

Step 2: Set $i=1$ (index for the array number in the chromosome) $0<i \leq 4 \times P+M$;

Step 3: If " $i \leq P$ ";

3-1: Generate a random integer between 1 to $V \rightarrow X(i)(X$ is the chromosome and $X(i)$ is

$i^{\text {th }}$ position of the matrix or the chromosome) and go to sub-step 3-2;

3-2: $i \leftarrow i+1$ and go back to step 3;

Else go to step 4;

Step 4: If " $i \leq 2 \times P$ ";

4-1: Select randomly among suppliers with the production capability of raw materials for

the respective part $\rightarrow X(i)$, and go to sub-step 4-2;

4-2: $i \leftarrow i+1$ and go back to step 4;

Else go to step 5;

Step 5: Set the number of machines inside each cell $=0$ and go to step 6;

Step 6: If " $i \leq 2 \times P+M$ ";

6-1: Generate a random integer between 1 to $C \rightarrow d$, and go to sub-step 6-2;

6-2: If "the number of assigned machines to cell $d \leq M_{\text {max }}$ ";

6-2-1: (The number of machines inside cell $d)+1 \rightarrow$ (the number of machines

inside cell $d$ ) and $X(i) \leftarrow d$. Then, go to sub-step 6-4;

6-3: Else $i=2 \times P+1$, set the number of machines inside each cell $=0$.

Then, go back to step 6;

6-4: $i \leftarrow i+1$ and go back to step 6;

Else, go to step 7;

Step 7: If " $i \leq 3 \times P+M$ ";

7-1: Generate a random integer between 1 to $V \rightarrow X(i)$ and go to sub-step 7-2;

7-2: $i \leftarrow i+1$ and go back to step 7;

Else go to step 8;

Step 8: Generate a permutation with $P$ elements randomly and fill positions from $X(i)$ to $X(i+$ $P)$. Go to step 9;

Step 9: If "pop < r";

9-1: $r \leftarrow r+1$ and go back step 2;

Else, "End";

FIGURE 7. Steps for generating the initial population.

\subsection{Mutation operator}

Mutation keeps one or more genes from the current generation to the next. In this study, a single point mutation operator is used. A random number between 1 to $4 \times P+M$ is generated for the mutation operator. If the number is between 1 to $3 \times P+M$, the selected gene is changed by another one with relative features. For example, if the number is less than $P$, then the selected vehicle is replaced with another type. As mentioned earlier, the chromosome has 5 segments. The last segment is a permutation of parts. So, if the number is larger 


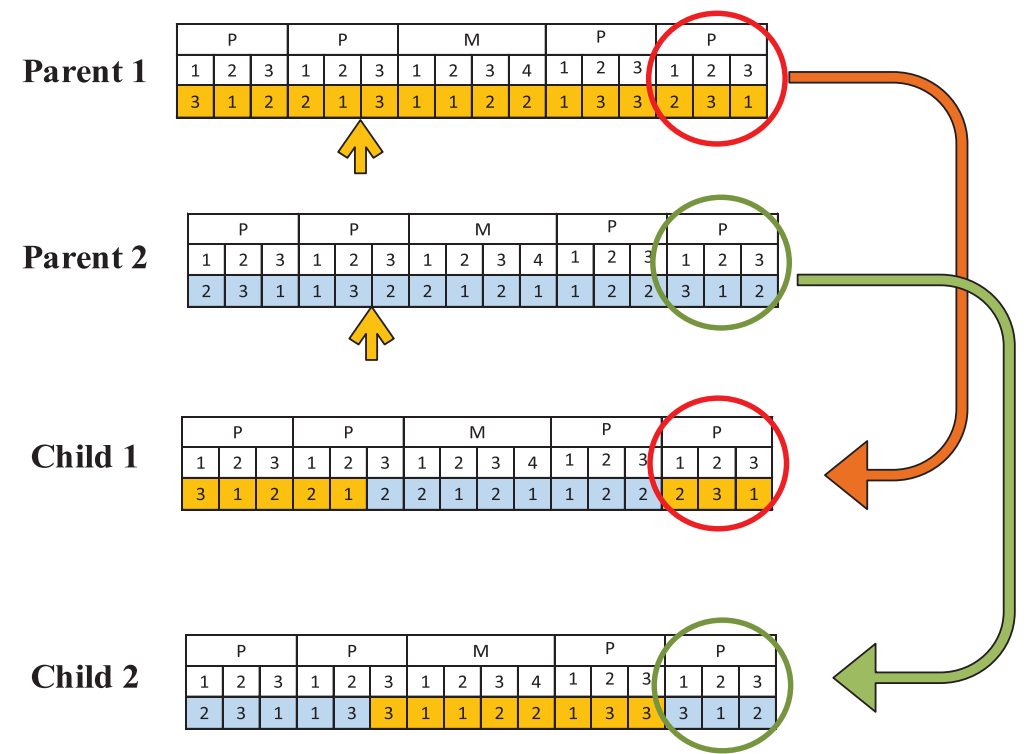

FIGURE 8. The offspring resulted from a crossover between parent 1 and parent 2.

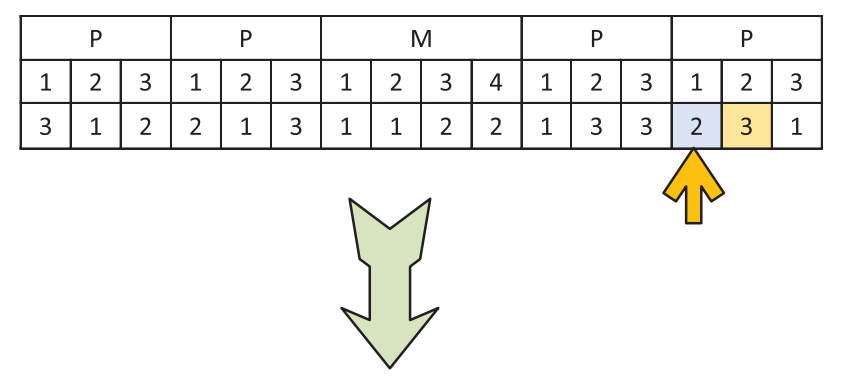

\begin{tabular}{|l|l|l|l|l|l|l|l|l|l|l|l|l|l|l|l|}
\hline \multicolumn{3}{|c|}{$P$} & \multicolumn{3}{|c|}{$P$} & \multicolumn{3}{c|}{$M$} & \multicolumn{3}{|c|}{$\mathrm{P}$} & \multicolumn{3}{|c|}{$\mathrm{P}$} \\
\hline 1 & 2 & 3 & 1 & 2 & 3 & 1 & 2 & 3 & 4 & 1 & 2 & 3 & 1 & 2 & 3 \\
\hline 3 & 1 & 2 & 2 & 1 & 3 & 1 & 1 & 2 & 2 & 1 & 3 & 3 & 3 & 2 & 1 \\
\hline
\end{tabular}

Figure 9. A mutated solution resulted from the application of mutation 2.

than $3 \times P+M$, then another gene in this segment is randomly selected to swap places. Figure 9 illustrates the mechanism of the single point mutation.

\section{Computational Results}

Twelve test problems that are presented in Table 3 are considered to evaluate the merits of the model and the performance of the proposed genetic algorithm (PGA). The small and very large-scale test problems have been selected from the literature $[3,4,9,23]$, and the rest of test problems have been randomly generated. The proposed model and PGA have been respectively coded in the Lingo 12.0 and MATLAB 2013a. They were solved on a computer with $2.99 \mathrm{~GB}$ RAM, core i5, and $2.50 \mathrm{GHz}$ processor. The proposed model and PGA were 
TABLE 2. The candidates and obtained values for the PGA parameters.

\begin{tabular}{|c|c|c|c|c|c|c|c|c|}
\hline \multirow[t]{3}{*}{ Factor } & \multicolumn{8}{|c|}{ Problem scale } \\
\hline & \multicolumn{2}{|l|}{ Small } & \multicolumn{2}{|l|}{ Medium } & \multicolumn{2}{|l|}{ Large } & \multicolumn{2}{|l|}{ Very large } \\
\hline & Candidates & Obtained & Candidates & Obtained & Candidates & Obtained & Candidates & Obtained \\
\hline $\begin{array}{l}\text { Maximum } \\
\text { iteration }\end{array}$ & $\{70,80,90,100\}$ & 100 & $\{500,550,600,650\}$ & 500 & $\{700,750,800,850\}$ & 750 & $\{850,900,950,1000\}$ & 1000 \\
\hline Population size & $\{80,90,100,110\}$ & 100 & $\{300,350,400,450\}$ & 450 & $\{400,450,500,550\}$ & 500 & $\{400,450,500,550\}$ & 550 \\
\hline $\begin{array}{l}\text { Mutation } \\
\text { probability }\end{array}$ & $\{0.2,0.3,0.4,0.5\}$ & 0.2 & $\{0.3,0.4,0.5,0.6\}$ & 0.4 & $\{0.2,0.3,0.4,0.5\}$ & 0.3 & $\{0.2,0.3,0.4,0.5\}$ & 0.3 \\
\hline $\begin{array}{l}\text { Tournament } \\
\text { size }\end{array}$ & $\{2,3\}$ & 3 & $\{2,3\}$ & 3 & $\{2,3\}$ & 3 & $\{2,3\}$ & 2 \\
\hline $\begin{array}{l}\text { Crossover } \\
\text { probability }\end{array}$ & $\{0.2,0.3,0.4,0.5\}$ & 0.4 & $\{0.4,0.5,0.6,0.7\}$ & 0.4 & $\{0.3,0.4,0.5,0.6\}$ & 0.5 & $\{0.4,0.5,0.6,0.7\}$ & 0.7 \\
\hline
\end{tabular}

TABle 3. Comparison of the B\&B of the Lingo software and the PGA runs.

\begin{tabular}{|c|c|c|c|c|c|c|c|c|c|c|c|c|c|c|}
\hline \multirow[b]{2}{*}{$\begin{array}{l}\text { Problem } \\
\text { No. }\end{array}$} & \multirow[b]{2}{*}{$\begin{array}{l}\text { No. of } \\
\text { parts }\end{array}$} & \multirow[b]{2}{*}{$\begin{array}{l}\text { No. of } \\
\text { machines }\end{array}$} & \multirow[b]{2}{*}{$\begin{array}{l}\text { No. of } \\
\text { cells }\end{array}$} & \multirow[b]{2}{*}{$M_{\max }$} & \multirow[b]{2}{*}{$\begin{array}{l}\text { No. of } \\
\text { vehicles }\end{array}$} & \multirow[b]{2}{*}{$\begin{array}{l}\text { No. of } \\
\text { suppliers }\end{array}$} & \multicolumn{3}{|c|}{$B \& B$} & \multicolumn{3}{|c|}{ PGA } & \multirow[b]{2}{*}{$G_{\text {ave }}(\%)$} & \multirow[b]{2}{*}{$G_{\text {best }}(\%)$} \\
\hline & & & & & & & $F_{\text {best }}$ & $F_{\text {bound }}$ & TB\&B (s) & $Z_{\text {ave }}$ & $Z_{\text {best }}$ & TGA (s) & & \\
\hline 1 & 4 & 3 & 2 & 2 & 3 & 12 & 4620.66 & 4620.66 & 16 & 4620.66 & 4620.66 & 3 & 0.00 & 0.00 \\
\hline 2 & 4 & 4 & 2 & 3 & 3 & 12 & 3390.95 & 3390.95 & 17 & 3390.95 & 3390.95 & 3 & 0.00 & 0.00 \\
\hline 3 & 5 & 5 & 2 & 3 & 7 & 15 & 3777.37 & 3777.37 & 212 & 3777.37 & 3777.37 & 3 & 0.00 & 0.00 \\
\hline 4 & 5 & 11 & 3 & 4 & 5 & 15 & 5751.55 & 5751.55 & 2038 & 5787 & 5751.7 & 76 & 0.62 & 0.00 \\
\hline 5 & 5 & 12 & 4 & 4 & 8 & 15 & 5326.91 & 5326.91 & 3099 & 5336.3 & 5327.4 & 89 & 0.18 & 0.01 \\
\hline 6 & 5 & 14 & 3 & 8 & 5 & 15 & 6346.5 & 6346.5 & 4337 & 6346.5 & 6346.5 & 99 & 0.00 & 0.00 \\
\hline 7 & 5 & 18 & 7 & 3 & 8 & 15 & 19848.5 & 13665.5 & 5400 & 18310.3 & 17821 & 58 & -7.75 & -10.21 \\
\hline 8 & 5 & 20 & 5 & 5 & 7 & 15 & 10801.3 & 2705.79 & 5400 & 5736.5 & 5554.3 & 132 & -46.89 & -48.58 \\
\hline 9 & 5 & 21 & 6 & 4 & 6 & 15 & 4462.0 & 2040.2 & 5400 & 4140.9 & 3947.7 & 55 & -7.19 & -11.53 \\
\hline 10 & 20 & 8 & 3 & 4 & 10 & 60 & - & - & - & 23701.33 & 23701 & 1360 & - & - \\
\hline 11 & 19 & 12 & 3 & 9 & 9 & 57 & - & - & - & 14162 & 14162 & 1427 & - & - \\
\hline 12 & 20 & 20 & 5 & 5 & 17 & 60 & - & - & - & 25955 & 25618 & 1663 & - & - \\
\hline
\end{tabular}

coded in Lingo 12.0 and MATLAB 2013a, respectively. Moreover, the design of experiments (DOEs) have been performed to set the parameters, since the efficiency of the metaheuristics algorithms tightly depends on the parameters.

The importance of each setting parameter and the interactions between them are estimated by the DOE. The test problems are categorized into four groups, including small, medium, large, and very large-scale. The PGA parameters are set using the Taguchi technique design. Test problems 2, 5, 8, and 11 of examples are selected to cover different scales for the DOE. The setting parameters are summed up in Table 2.

The test problems are solved by branch and bound (B\&B) of the Lingo software and PGA. Then, their results are compared in Table 3. The large-scale test problems were allowed to run for 5400s. The very large-scale test problems exceeded the allowable limitations of the Lingo software to produce any feasible solution, which means the number of constraints and variables ran out of memory. Each test problem has been run 3 times by the PGA and then the average of the solutions in $Z_{\text {ave }}$ and the best solution in $Z_{\text {best }}$ were reported. According to the Lingo software tutorial, $F_{\text {best }}$ is the best amount of the objective function found so far and $F_{\text {bound }}$ is the objective function of the dual model. When $F_{\text {bound }}$ is equal to $F_{\text {best }}$, the objective function has reached the global optimal solution. Moreover, for large-scale test problems if $Z_{\text {ave }}$ or $Z_{\text {best }}$ is between $F_{\text {bound }}$ and $F_{\text {best }}$, it means that the PGA has obtained a better solution than the B\&B of Lingo software. Using these concepts, it is worth mentioning that appropriate metrics are essential that can provide a base for comparing the results. For this purpose, two formulas are used. $G_{\text {ave }}$ is equal to $\left[\left(Z_{\text {ave }}-F_{\text {best }}\right) / F_{\text {best }}\right] \times 100$ and $G_{\text {best }}=\left[\left(Z_{\text {best }}-F_{\text {best }}\right) / F_{\text {best }}\right] \times 100$. If $G_{\text {ave }}$ or $G_{\text {best }}$ is negative, it means the PGA has been able to obtain a better solution than the B\&B of the Lingo software and vice versa. 


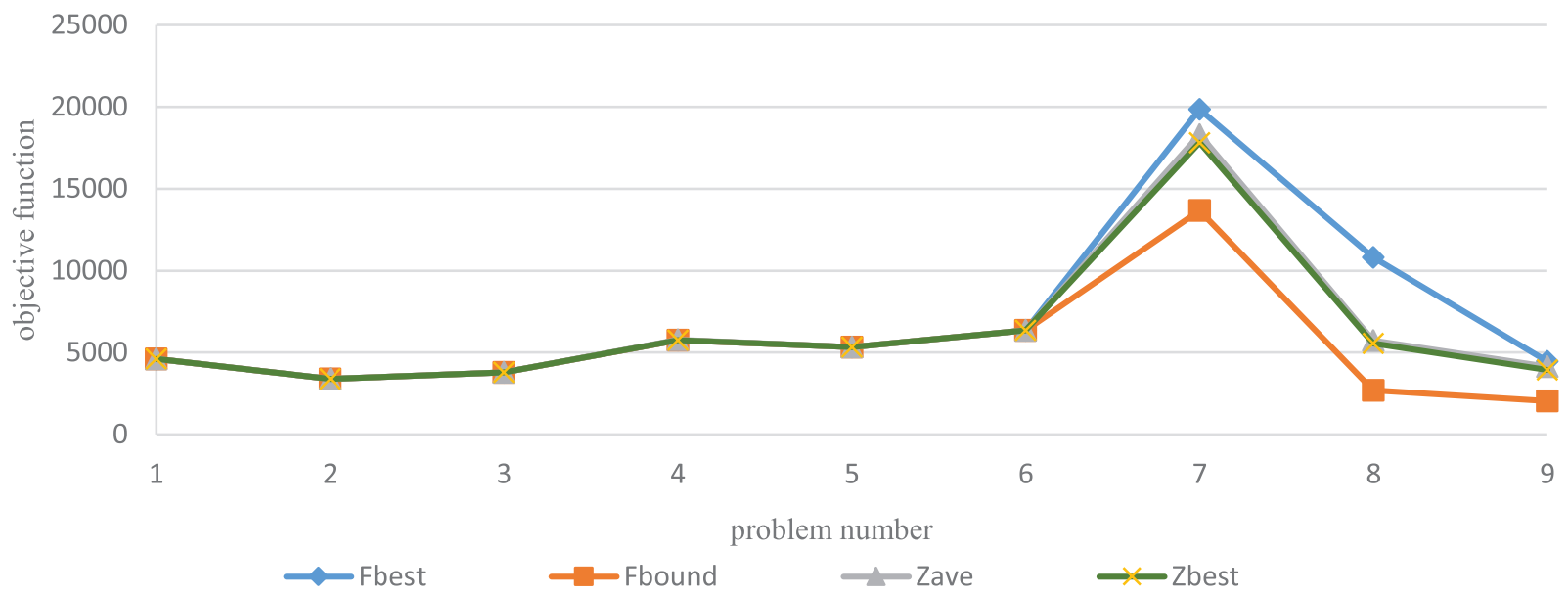

Figure 10. Comparison of the performance of the PGA and the B\&B of the Lingo software.

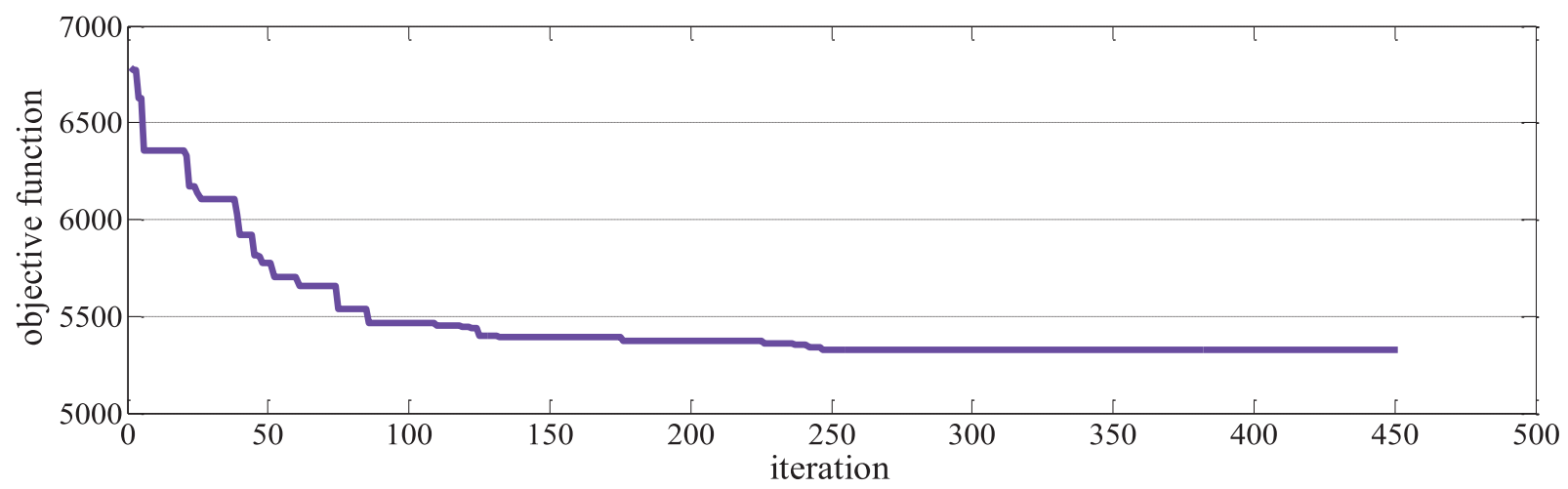

Figure 11. Convergence of the PGA for test problem 5.

The PGA results were compared with the B\&B of Lingo software, as shown in Table 3 . The results in Table 3 show that the B\&B of the Lingo software and the PGA report the same results in the small-scale problems. They also depict small differences for the medium-scale problems. The results show that the PGA can provide better solutions for the large-scale problems (see Fig. 10), and the B\&B of the Lingo software cannot find any feasible solution for the very large-scale problems whereas the PGA achieves them. The B\&B of the Lingo software takes more computation time than the PGA. Figure 11 shows the minimizing process for the test problem 5 in Table 3 using the PGA.

\subsection{Sensitivity analysis}

The test problem 4 is considered in the sensitivity analysis of the proposed model to investigate the effect of the related parameters on the performance of the proposed model and to highlight important managerial insights. Information about test problem 4 can be found in the supplementary data. The due date of part 5 is changed and kept the other parameters fixed to analyze the effect of the due date on the transfer cost of finished parts, the delay cost of final parts, waiting time, and inter-cell movement time. It should be noted, the vertical axes on the right-hand and left-hand show the delay cost and transfer cost of final part 5 in Figure 12, respectively. Figure 12 shows the relation between the due date of finished part 5 and related delay cost. The 


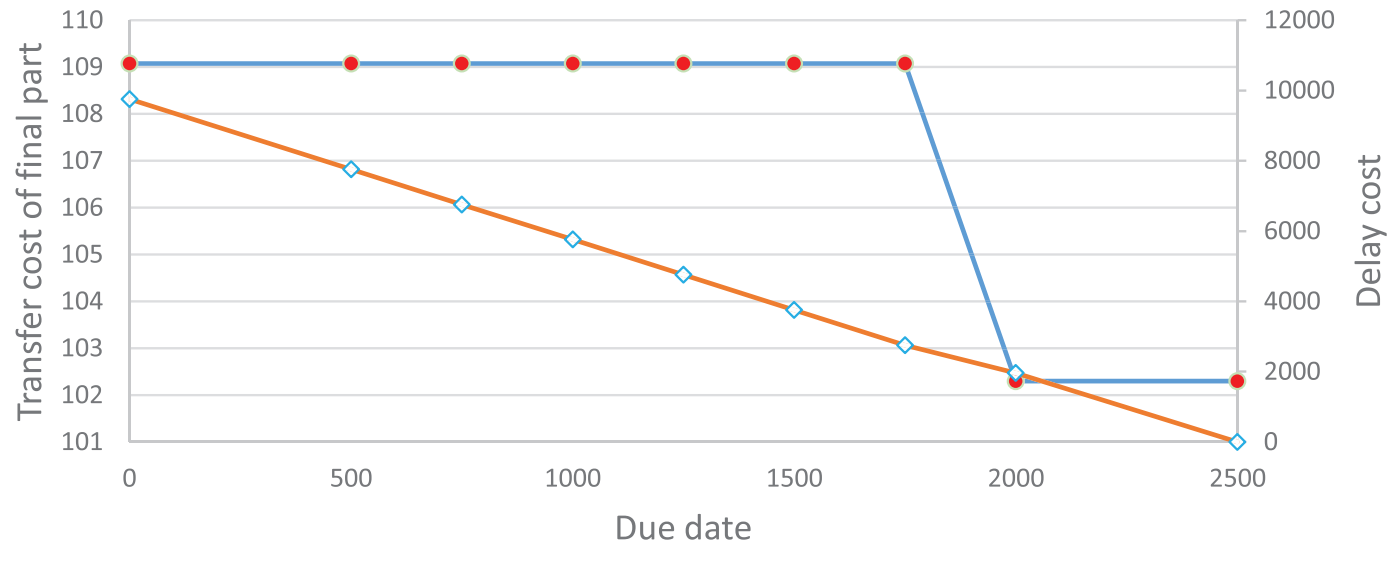

- - The transfer cost of finished part $5 \quad \sim$ The delay cost of finished part 5

Figure 12. The delay and transfer cost of finished part 5 in the presence of different due dates.

results show that, while the due date of finished part 5 decreases, the relevant delay cost increases, which is predictable by the fifth term of the objective function. The first point of contact on the horizontal axis is where $c_{4,5}$ is equal to $d_{5}$, namely the delay cost of finished part 5 is zero. Besides, The transfer cost of finished part 5 goes up while the respective due date declines because the delay cost is larger than the transfer cost of finished part 5 before $c_{4,5}=d_{5}$ on lower due dates. In other words, the model attempts to use faster vehicles to meet the deadline instead of accepting larger delay costs. Moreover, higher-speed vehicles are rented at a higher price. The threshold of selected vehicle, while the due date of finished part 5 decreases, is the fastest vehicle with the highest rental price.

As the due date of finished part 5 varies, it could influence on the type of vehicle to transport raw materials to the manufacturer and the supply of raw materials from a supplier with lower distance, which in turn impacts on the price of raw materials. But, when the due date of finished part 5 reduces, the procurement costs, which are the first and second cost terms in the objective function, do not change. It can be explained by the following reasons. If raw materials are transported in a vehicle with the highest speed instead of the current one, which has the lowest speed, still the transfer cost of the selected vehicle plus the extra delay cost owing to the slowest vehicle has a lower cost. Furthermore, the lowest raw material price with the shortest delivery lead time among potential suppliers is chosen in the optimal solution. Therefore, when the due date of finished part 5 drops, the procurement costs do not change.

How the waiting time and inter-cell movement behave for different sets of the due dates are depicted in Figure 13. While the due date of finished part 5 decreases, so do the priority of part 5 and the mean waiting time reduce. This is because the mean waiting time effects on the delay cost. Decreasing the due date of finished part 5 not only influences the delay cost, but it also impacts on inter-cell movement cost. So, it reduces inter-cell movement time by trying to assign all operations of each part in one cell.

The behavior of the model is investigated by increasing the cost coefficients for all indexes in the objective function through multiplying them by the integer numbers $(X)$ and assuming the other parameters to be fixed. Significant managerial insights were obtained by the investigation of this numerical example. The results are explained in the rest of this section.

When $\mathrm{CD}_{i}$ (the delay cost of part $i$ ) boosts, it could influence on vehicle type, inter-cell movement, waiting time, and delay as mentioned above. However, it does not make the model to alter the optimal solution, since the delay is zero in the optimal solution for all parts. But, if the delay is not zero for one part, this increase 


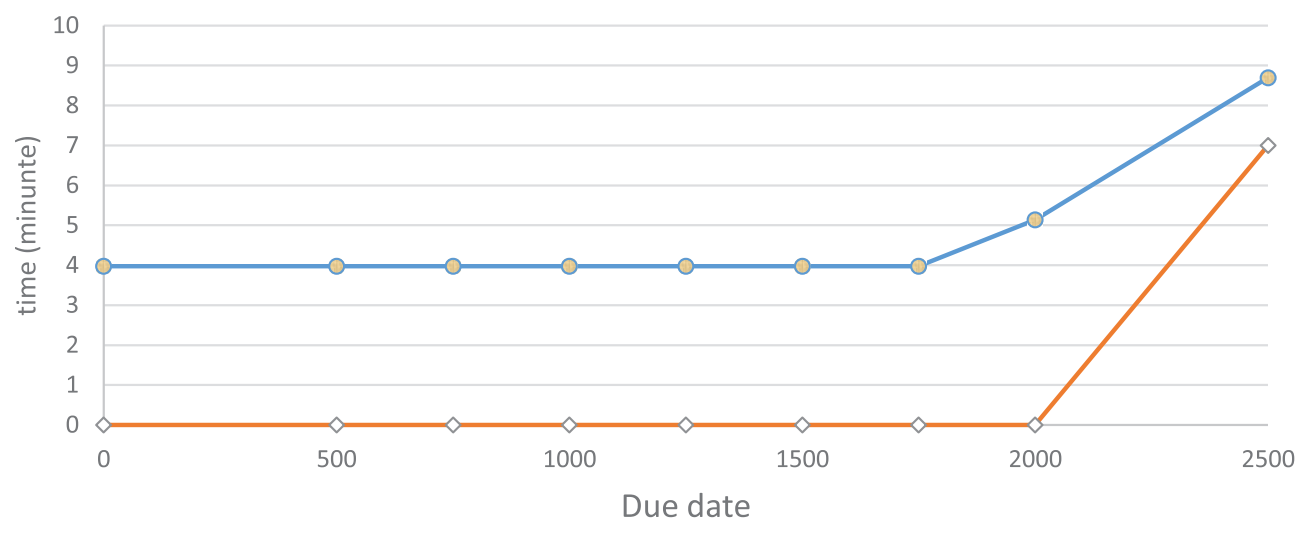

$\rightarrow-$ The mean waiting time $\quad \sim$ The inter-cell movement time

FiguRE 13. The mean waiting time and the inter-cell movement time of finished part 5 in the presence of different due dates.

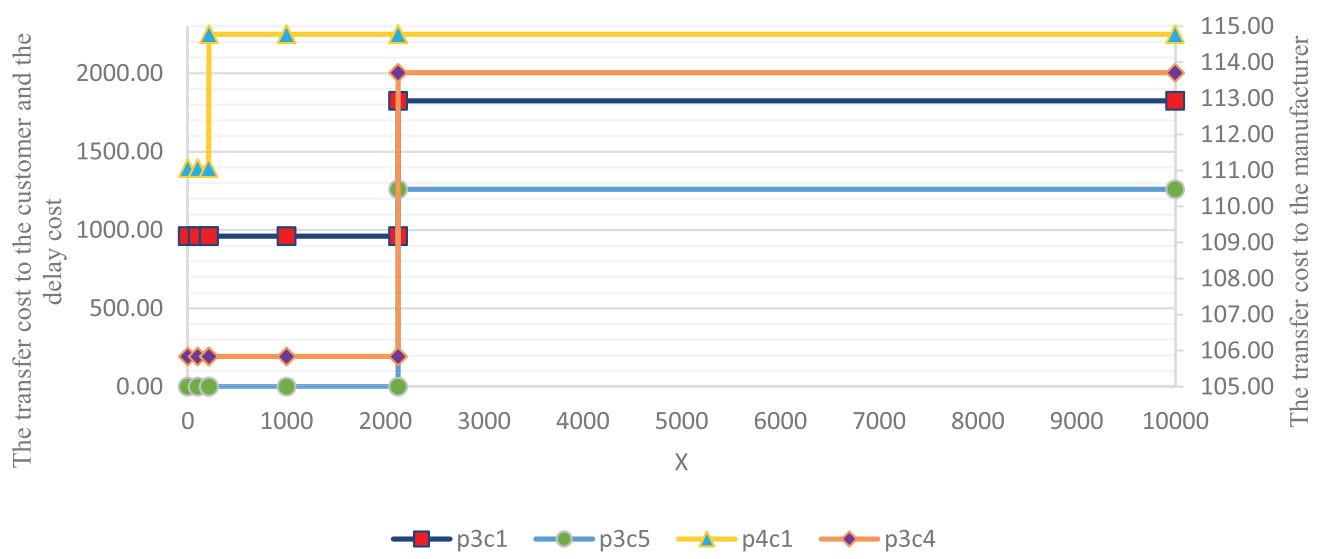

FiguRe 14. Behavior of transfer cost to the manufacturer and customer, and the delay cost individually with varying $\mathrm{CS}_{s i} \forall s, i$.

could decrease inter-cell movement and waiting time and lead to the selection of a faster vehicle to drop the delay cost.

As $\mathrm{CV}_{k k^{\prime}}$ (inter-cell movement cost from cell $k$ to cell $k^{\prime}$ ) goes up, the model attempts to assign all operations of each part in a single cell to reduce inter-cell movements. The results show that all operations of each part are processed in a single cell except operations 1 and 4 related to parts 2 and 5 , respectively. Nevertheless, this increase does not make the model to change the optimal solution. For part 5 , all operations are done in a single cell except operation 4 because the number of machines in the cell is equal to $M_{\max }$. Therefore, constrain (13) avoids adding another machine. Likewise, the number of various machines to operate on part 2 is more than $M_{\max }$, so inter-cell movement is inevitable.

The sensitivity analysis of $\mathrm{CS}_{s i}$ (the raw material price of part $i$ offered by supplier $s$ ) is performed as shown in Figure 14. Part 3 and part 4 did not achieve the lowest raw material price among suppliers in the optimal solution. This is because the selected suppliers are in a shorter distance compared to those offering the lowest raw material price. Therefore, they arrive at the manufacturer earlier with lower transportation costs. When 
TABLE 4. The assigned machines to cells.

\begin{tabular}{|c|c|c|c|c|}
\hline & Cell 1 & Cell 2 & Cell 3 & Cell 4 \\
\hline Machines & $\{5,9,16,20,21,22,23,25\}$ & $\{1,4,6,7,10,13,15,17\}$ & $\{18\}$ & $\{2,3,8,11,12,14,19,24\}$ \\
\hline
\end{tabular}

$\mathrm{CS}_{s i}$ increases, each term of the objective function changes except inter-cell movement cost, which provides an insight that the inter-cell movement cost is not sensitive to the raw material price. The symbol $p_{4} c_{1}$ in the legend shows the change in the transfer cost to procure the raw material of part 4 . The symbol $p_{4}$ stands for part 4 , and $c_{1}$ represents the first cost term in the objective function, which is the transfer cost to the manufacturer. It should be noted, the vertical axis on the right side shows costs related to the transfer cost to the manufacturer $\left(c_{1}\right)$, and the delay cost of finished parts $\left(c_{5}\right)$, individually. The vertical axis on the left side illustrates the transfer cost of finished parts $\left(c_{4}\right)$. When the parameter $\mathrm{CS}_{s 4}$ takes the value $214 \times \mathrm{CS}_{s 4}$ (i.e., replace initial value $\mathrm{CS}_{s 4}$ with $214 \times \mathrm{CS}_{s 4}$ ), supplier 10 in the initial optimal solution switches to supplier 14, which offers the lowest raw material price for part 4 . This change in the optimal solution causes further distance for the transportation of raw materials, whereas it does not make any delay. In this solution, the difference in transfer cost between suppliers 10 and 14 is less than $\left(\mathrm{CS}_{10,4}-\mathrm{CS}_{14,4}\right)$, i.e., the cheapest supplier is preferred compared to the nearest supplier to the manufacturer. As $\mathrm{CS}_{s i}$ boosts through multiplying it by $X, X$ takes the value 2132 (i.e., replace initial value $\mathrm{CS}_{s 3}$ with $2132 \times \mathrm{CS}_{s 3}$ ), where supplier 8 in the initial optimal solution switches to supplier 2 , which offers the lowest raw material price for part 3 . In this solution, the model achieves the lowest raw material price for part 3 at the expense of increasing $c_{1}, c_{4}$, and $c_{5}$. When $X$ is equal to 2132 , the sum of three differences that include the difference of $c_{1}, c_{4}$, and $c_{5}$ between suppliers 8 and 2 is less than $\left(\mathrm{CS}_{8,3}-\mathrm{CS}_{2,3}\right)$. This means the lowest raw material price forces the model to accept higher transfer and delay cost. After attaining the lowest raw material price for all parts, the solution remains constant and is not affected by increasing the raw material price.

To obtain useful insights, $\mathrm{CO}_{v}$ (the cost of vehicle $v$ per unit time) is analyzed given that part 2 and part 4 do not achieve the lowest rental price in the initial optimal solution. $\mathrm{CO}_{v}$ goes up, whereas the initial optimal solution does not change. The reason is that the transfer costs in the first and fourth terms of the objective function multiply $\mathrm{CO}_{v}$ by the transfer time. So, when $\mathrm{CO}_{v}$ increases for all vehicle types, it does not cause the model to choose the vehicle with the lowest rental price because the selected vehicle in the initial optimal solution has the lowest speed among all vehicle types. Therefore, it needs a lot of time to transport finished parts to the relevant customer. All in all, the model is not sensitive to varying $\mathrm{CO}_{v}$.

\subsection{A case study}

The model is employed for a spare parts manufacturer of automobiles to present that the proposed model can be implemented in a real-world application. The case study will present meaningful insight about centralization of decisions and how it leads to the reduction of costs in throughout the supply chain. The case information can be found in the supplementary data.

It is common to make a decision separately in the production activities of automobile industries [56]. In this factory, the decision was made for each component in the supply chain based on following rules: the lowest rental price for vehicles to pick up raw materials, the lowest raw material price among suppliers, the lowest inter-cell movement cost to assign machines to each cell, the earliest due date to prioritize parts behind each machine, and the lowest rental price for vehicles to deliver finished parts. The total cost of this approach is 5018.23, while the total cost of the proposed model is 3928.04. The global optimal solution of the proposed model is presented as follows. Vehicle type 4 is assigned to transport the raw materials of all parts, and the raw materials of parts 1 to 4 are respectively supplied by suppliers 1, 7, 2, and 8 . Besides, Table 4 shows the assigned machines to cells, vehicle type 4 is assigned to deliver all final parts, and the priorities of parts 1 to 4 are in the order 3,4 , 2 , and 1 to be processed on the respective machine. 


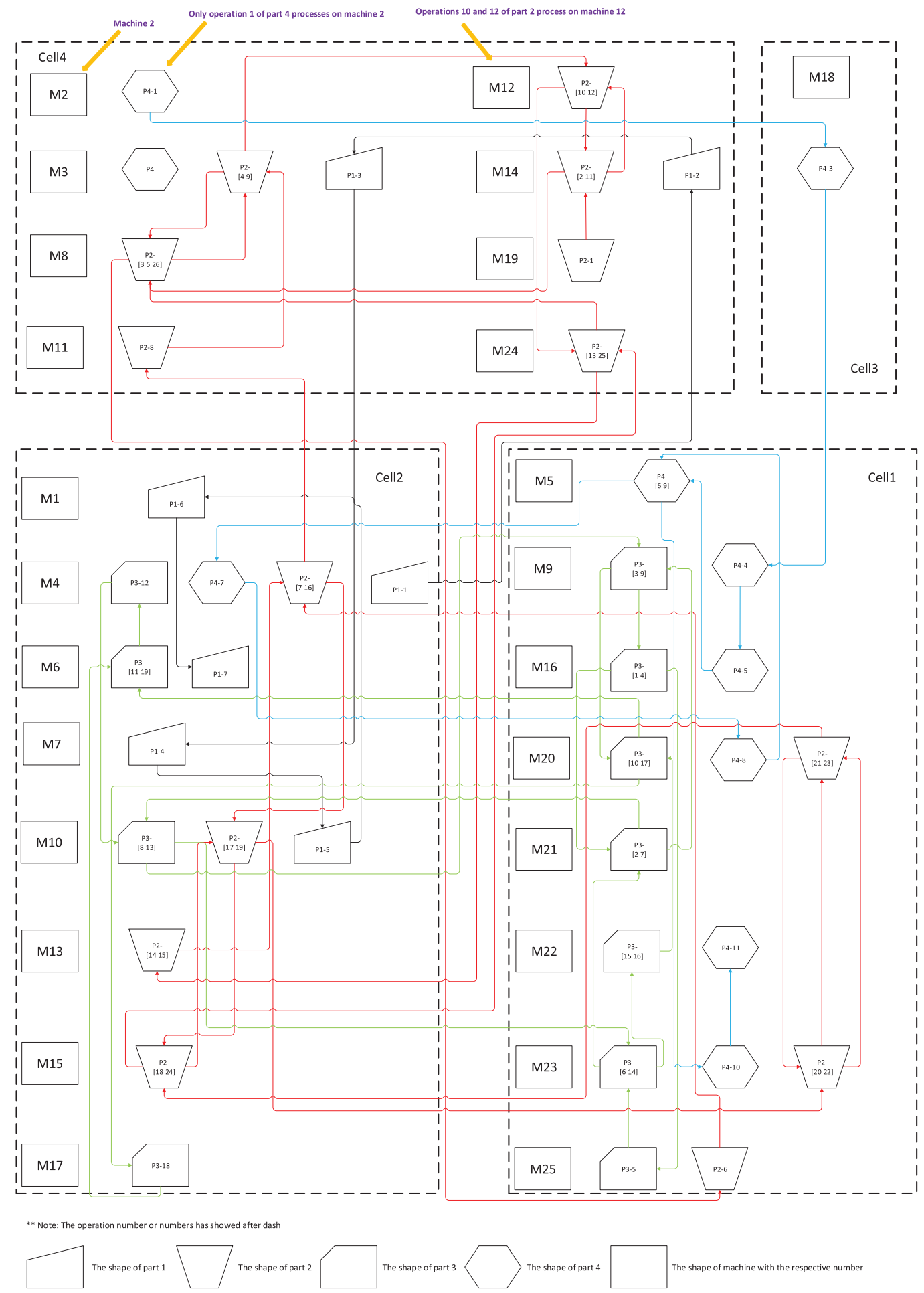

Figure 15. A detailed solution of the case study. 
In Figure 15, each row in each cell shows the queue of parts and their priority to be processed on the respective machine based on the solution. There could be more than one type of part in each queue. However, it is avoided in the figure because it looks cluttered. Each part type is shown by a certain shape. The process flow of each part is illustrated in the figure. As seen in the figure, the number of inter-cell movements is less than intra-cell movements, which proves the high performance of the proposed model. Machine 18 could not be located in either cell 1 or 4 because $M_{\max }$ avoids more than six machines in each cell. Therefore, it is assigned to cell 3.

\section{Conclusion}

In this study, a three-stage supply chain was studied. The first stage, supply, considered vehicles with various speeds to transport raw materials and suppliers with different delivery lead times. In the second stage, production, the assignment of machines to cells and the identification of priority for each part to be processed on the relevant machine were investigated. In other words, the CF problem was studied along with the prioritization of parts. The third stage, customer, considered vehicles with various speeds to deliver final parts and customers with different due dates. In addition, the interval between two consecutive arrivals of demand, the processing time of the machines, and the transportation time of the vehicles have an exponential distribution. A novel mixed-integer nonlinear mathematical model was developed with the queueing theory framework. The objective function minimizes the total cost, including procurement cost, transfer cost to the manufacturer, inter-cell movement cost, the transfer cost of finished parts, and delay costs. The nonlinear mathematical model was linearized to find exact solutions. A GA was developed to deal with the NP-hardness of the problem. Moreover, the Taguchi experimental design method was used to set the appropriate values of the PGA parameters to improve the performance. The performance of the PGA was tested by solving test problems with different sizes. The PGA solved all the test problems within a very short computational time. However, the linearized mathematical model, which has been coded using Lingo, could not provide an optimal solution to the large-scale test problems within $1.5 \mathrm{~h}$ and any bound to the very large-scale test problems.

The significant managerial insights were found via the sensitivity analysis and case study. A reduction in due dates increases transfer cost and minimizes waiting and material handling time. Transfer and delay costs boost with a rise in the raw material price. It is also addressed that the centralization of decisions reduces the total cost. Besides, the proposed mathematical model was implemented in a real case. The acquired results demonstrated that the proposed model could find the best suppliers to procure, the vehicles to transport, the machines to be assigned to cells, and the priority for each part to be processed on the relevant machine simultaneously. For future research, it is recommended to consider vehicle capacity, routes for a fleet of vehicles, and inventory models to better match the results to real-world needs and applications.

\section{REFERENCES}

[1] A. Aalaei and H. Davoudpour, Revised multi-choice goal programming for incorporated dynamic virtual cellular manufacturing into supply chain management: a case study. Eng. App. Artif. Intell. 47 (2016) 3-15.

[2] A. Aalaei and H. Davoudpour, A robust optimization model for cellular manufacturing system into supply chain management. Int. J. Prod. Econ. 183 (2017) 667-679.

[3] A. Ahi, M.B. Aryanezhad, B. Ashtiani and A. Makui, A novel approach to determine cell formation, intracellular machine layout and cell layout in the CMS problem based on TOPSIS method. Comput. Oper. Res. 36 (2009) $1478-1496$.

[4] J. Arkat, M.H. Farahani and L. Hosseini, Integrating cell formation with cellular layout and operations scheduling. Int. J. Adv. Manuf. Technol. 61 (2012) 637-647.

[5] J. Arkat, M.H. Farahani and F. Ahmadizar, Multi-objective genetic algorithm for cell formation problem considering cellular layout and operations scheduling. Int. J. Comput. Integr. Manuf. 25 (2012) 625-635.

[6] A. Ballakur, An investigation of part family/machine group formation in designing a cellular manufacturing system. Ph.D. thesis, University of Wisconsin (1985).

[7] M.V. Batsyn, E.K. Batsyna and I.S. Bychkov, NP-completeness of cell formation problem with grouping efficacy objective. Int. J. Prod. Res. 58 (2020) 6159-6169.

[8] S. Benhalla, A. Gharbi and C. Olivier, Multi-plant cellular manufacturing design within a supply chain. J. Oper. Logistics 4 (2011) II.1-II.17.

[9] M. Boulif and K. Atif, A new branch\&bound-enhanced genetic algorithm for the manufacturing cell formation problem. Comput. Oper. Res. 33 (2006) 2219-2245. 
[10] J. Chai, J.N. Liu and E.W. Ngai, Application of decision-making techniques in supplier selection: a systematic review of literature. Expert Syst. App. 40 (2013) 3872-3885.

[11] S. Chopra and P. Meindl, Supply chain management: strategy, planning \& operation. In: Das summa summarum des management. Springer (2007) 265-275.

[12] S. Croom, P. Romano and M. Giannakis, Supply chain management: an analytical framework for critical literature review. Eur. J. Purchasing Supply Manage. 6 (2000) 67-83.

[13] D. Deliktas, O. Torkul and O. Ustun, A flexible job shop cell scheduling with sequence-dependent family setup times and intercellular transportation times using conic scalarization method. Int. Trans. Oper. Res. 26 (2019) $2410-2431$.

[14] G. Egilmez, E.M. Mese, B. Erenay and G.A. Süer, Group scheduling in a cellular manufacturing shop to minimise total tardiness and nT: a comparative genetic algorithm and mathematical modelling approach. Int. J. Serv. Oper. Manage. 24 (2016) 125-146.

[15] I. Eguia, J. Racero, F. Guerrero and S. Lozano, Cell formation and scheduling of part families for reconfigurable cellular manufacturing systems using Tabu search. Simulation 89 (2013) 1056-1072.

[16] I. Erozan, O. Torkul and O. Ustun, Proposal of a nonlinear multi-objective genetic algorithm using conic scalarization to the design of cellular manufacturing systems. Flexible Serv. Manuf. J. 27 (2015) 30-57.

[17] S.A. Fahmy, Mixed integer linear programming model for integrating cell formation, group layout and group scheduling. In: 2015 IEEE International Conference on Industrial Technology (ICIT) (2015) 2403-2408.

[18] T. Farzad, O. Mohammad Rasid, A. Aidy and Y. Rosnah Mohd, A review of supplier selection methods in manufacturing industries. Suranaree J. Sci. Technol. 15 (2008) 201-208.

[19] Y. Feng, G. Li and S.P. Sethi, A three-layer chromosome genetic algorithm for multi-cell scheduling with flexible routes and machine sharing. Int. J. Prod. Econ. 196 (2018) 269-283.

[20] D. Gross and C.M. Harris, Fundamentals of Queueing Theory. John Wiley and Sons, Inc., New York (2008).

[21] K. Halat and R. Bashirzadeh, Concurrent scheduling of manufacturing cells considering sequence-dependent family setup times and intercellular transportation times. Int. J. Adv. Manuf. Technol. 77 (2015) 1907-1915.

[22] R. Hammami, Y. Frein and A.B. Hadj-Alouane, An international supplier selection model with inventory and transportation management decisions. Flexible Serv. Manuf. J. 24 (2012) 4-27.

[23] M. Hazarika and D. Laha, A heuristic approach for machine cell formation problems with alternative routings. Proc. Comput. Sci. 89 (2016) 228-242.

[24] S.S. Heragu, Group technology and cellular manufacturing. IEEE Trans. Syst. Man Cybern. 24 (1994) $203-215$.

[25] W. Ho, X. Xu and P.K. Dey, Multi-criteria decision making approaches for supplier evaluation and selection: a literature review. Eur. J. Oper. Res. 202 (2010) 16-24.

[26] M. Igarashi, L. de Boer and A.M. Fet, What is required for greener supplier selection? A literature review and conceptual model development. J. Purchasing Supply Manage. 19 (2013) 247-263.

[27] S.A. Irani, Handbook of Cellular Manufacturing Systems. John Wiley \& Sons (1999).

[28] K. Jankauskas, L.G. Papageorgiou and S.S. Farid, Fast genetic algorithm approaches to solving discrete-time mixed integer linear programming problems of capacity planning and scheduling of biopharmaceutical manufacture. Comput. Chem. Eng. 121 (2019) 212-223.

[29] A.K. Kamrani, H.R. Parsaei and D.H. Liles, Planning, Design, and Analysis of Cellular Manufacturing Systems. Newnes 24 (1995).

[30] S.E. Kesen and Z. Güngör, Job scheduling in virtual manufacturing cells with lot-streaming strategy: a new mathematical model formulation and a genetic algorithm approach. J. Oper. Res. Soc. 63 (2012) 683-695.

[31] J.R. King and V. Nakornchai, Machine-component group formation in group technology: review and extension. Int. J. Prod. Res. 20 (1982) 117-133.

[32] R. Kumar and S.P. Singh, Modified SA algorithm for bi-objective robust stochastic cellular facility layout in cellular manufacturing systems. In: Advanced Computing and Communication Technologies. Springer (2019) 19-33.

[33] S.-W. Lin and K.-C. Ying, Makespan optimization in a no-wait flowline manufacturing cell with sequence-dependent family setup times. Comput. Ind. Eng. 128 (2019) 1-7.

[34] C. Liu and J. Wang, Cell formation and task scheduling considering multi-functional resource and part movement using hybrid simulated annealing. Int. J. Comput. Intell. Syst. 9 (2016) 765-777.

[35] C. Liu, J. Wang, J.Y.-T. Leung and K. Li, Solving cell formation and task scheduling in cellular manufacturing system by discrete bacteria foraging algorithm. Int. J. Prod. Res. 54 (2016) 923-944.

[36] C. Liu, J. Wang and J.Y.-T. Leung, Integrated bacteria foraging algorithm for cellular manufacturing in supply chain considering facility transfer and production planning. Appl. Soft Comput. 62 (2018) 602-618.

[37] F. Mallor, C. Azcárate and J. Barado, Control problems and management policies in health systems: application to intensive care units. Flexible Serv. Manuf. J. 28 (2016) 62-89.

[38] O. Pal, A.K. Gupta and R. Garg, Supplier selection criteria and methods in supply chains: a review. Int. J. Soc. Manage. Econ. Bus. Eng. 7 (2013) 1403-1409.

[39] V.C. Pasupuleti, Scheduling in cellular manufacturing systems. Iberoam. J. Ind. Eng. 4 (2012) 231-243.

[40] M.M. Paydar and M. Saidi-Mehrabad, Revised multi-choice goal programming for integrated supply chain design and dynamic virtual cell formation with fuzzy parameters. Int. J. Comput. Integr. Manuf. 28 (2015) 251-265.

[41] M.M. Paydar and M. Saidi-Mehrabad, A hybrid genetic algorithm for dynamic virtual cellular manufacturing with supplier selection. Int. J. Adv. Manuf. Technol. 92 (2017) 3001-3017. 
[42] M.M. Paydar, M. Saidi-Mehrabad and E. Teimoury, A robust optimisation model for generalised cell formation problem considering machine layout and supplier selection. Int. J. Comput. Integr. Manuf. 27 (2014) 772-786.

[43] B. Rabbouch, F. Saâdaoui and R. Mraihi, Efficient implementation of the genetic algorithm to solve rich vehicle routing problems. Oper. Res. 21 (2021) 1763-1791.

[44] R. Rachamadugu, U. Nandkeolyar and T. Schriber, Scheduling with sequencing flexibility. Decis. Sci. 24 (1993) $315-342$.

[45] H. Rafiei, M. Rabbani, H. Gholizadeh and H. Dashti, A novel hybrid SA/GA algorithm for solving an integrated cell formationjob scheduling problem with sequence-dependent set-up times. Int. J. Manage. Sci. Eng. Manage. 11 (2016) 134-142.

[46] R. Ramezanian and S. Khalesi, Integration of multi-product supply chain network design and assembly line balancing. Oper. Res.21 (2021) 453-483.

[47] P.P. Rao and R. Mohanty, Impact of cellular manufacturing on supply chain management: exploration of interrelationships between design issues. Int. J. Manuf. Technol. Manage. 5 (2003) 507-520.

[48] A. Sadeghi, G. Suer, R.Y. Sinaki and D. Wilson, Cellular manufacturing design and replenishment strategy in a capacitated supply chain system: a simulation-based analysis. Comput. Ind. Eng. 141 (2020) 106282.

[49] M. Saravanan and S. Karthikeyan, Scheduling optimization cell formation problem for cellular manufacturing system using meta-heuristic methods. Appl. Mech. Mater. 786 (2015) 340-344.

[50] L.K. Saxena and P. Jain, An integrated model of dynamic cellular manufacturing and supply chain system design. Int. J. Adv. Manuf. Technol. 62 (2012) 385-404.

[51] J. Schaller, Incorporating cellular manufacturing into supply chain design. Int. J. Prod. Res. 46 (2008) $4925-4945$.

[52] D. Shishebori and S. Dehnavi-Arani, A multi-stage stochastic programming approach in a dynamic cell formation problem with uncertain demand: a case study. Int. J. Supply Oper. Manage. 6 (2019) 67-87.

[53] D. Simchi-Levi, P. Kaminsky and E. Simchi-Levi, Managing the Supply Chain: Definitive Guide. Tata McGraw-Hill Education (2004).

[54] M. Solimanpur and A. Elmi, A tabu search approach for cell scheduling problem with makespan criterion. Int. J. Prod. Econ. 141 (2013) 639-645.

[55] M. Soolaki and J. Arkat, Incorporating dynamic cellular manufacturing into strategic supply chain design. Int. J. Adv. Manuf. Technol. 95 (2018) 2429-2447.

[56] L. Tang, Z. Jin, X. Qin and K. Jing, Supply chain scheduling in a collaborative manufacturing mode: model construction and algorithm design. Ann. Oper. Res. 275 (2019) 685-714.

[57] S. Taouji Hassanpour, R. Bashirzadeh, A. Adressi and B. Bahmankhah, Scheduling problem of virtual cellular manufacturing systems (VCMS); Using simulated annealing and genetic algorithm based heuristics. J. Mod. Processes Manuf. Prod. 3 (2014) $45-60$.

[58] M. Wazed, S. Ahmed and Y. Nukman, Uncertainty factors in real manufacturing environment. Aust. J. Basic Appl. Sci. 3 (2009) 342-351.

[59] U. Wemmerlöv and N.L. Hyer, Research issues in cellular manufacturing. Int. J. Prod. Res. 25 (1987) $413-431$.

[60] U. Wemmerlöv and N.L. Hyer, Cellular manufacturing in the US industry: a survey of users. Int. J. Prod. Res. 27 (1989) $1511-1530$.

[61] X. Wu, C.-H. Chu, Y. Wang and D. Yue, Genetic algorithms for integrating cell formation with machine layout and scheduling. Comput. Ind. Eng. $\mathbf{5 3}$ (2007) 277-289.

[62] G. Xue and O.F. Offodile, Integrated optimization of dynamic cell formation and hierarchical production planning problems. Comput. Ind. Eng. 139 (2020) 106155.

\section{Subscribe to Open (S20) A fair and sustainable open access model}

This journal is currently published in open access under a Subscribe-to-Open model (S2O). S2O is a transformative model that aims to move subscription journals to open access. Open access is the free, immediate, online availability of research articles combined with the rights to use these articles fully in the digital environment. We are thankful to our subscribers and sponsors for making it possible to publish this journal in open access, free of charge for authors.

\section{Please help to maintain this journal in open access!}

Check that your library subscribes to the journal, or make a personal donation to the S2O programme, by contacting subscribers@edpsciences.org

More information, including a list of sponsors and a financial transparency report, available at: https://www. edpsciences.org/en/maths-s2o-programme 